\title{
Design and Development of a Proficient Converter for Solar Photovoltaic Based Sustainable Power Generating System
}

\author{
Muhannad Alaraj ${ }^{1}\left(\right.$, Anirudh Dube ${ }^{2, *}$, Ibrahim Alsaidan $^{1}$, Mohammad Rizwan ${ }^{1,3}\left(\right.$ and Majid Jamil $^{2}$ \\ 1 Department of Electrical Engineering, College of Engineering, Qassim University, Buraydah, \\ Qassim 52571, Saudi Arabia; Muhannad@qu.edu.sa (M.A.); Alsaidan@qu.edu.sa (I.A.); \\ MR.Khan@qu.edu.sa (M.R.) \\ 2 Department of Electrical Engineering, Jamia Millia Islamia, Delhi 110025, India; mjamil@jmi.ac.in \\ 3 Department of Electrical Engineering, Delhi Technological University, Delhi 110042, India \\ * Correspondence: anirudhdube12@gmail.com
}

Citation: Alaraj, M.; Dube, A.; Alsaidan, I.; Rizwan, M.; Jamil, M. Design and Development of a Proficient Converter for Solar Photovoltaic Based Sustainable Power Generating System. Sustainability 2021, 13, 2045. https://doi.org/10.3390/su13042045

Academic Editor: Detlef Schulz

Received: 11 January 2021

Accepted: 10 February 2021

Published: 14 February 2021

Publisher's Note: MDPI stays neutral with regard to jurisdictional claims in published maps and institutional affiliations.

Copyright: (C) 2021 by the authors. Licensee MDPI, Basel, Switzerland. This article is an open access article distributed under the terms and conditions of the Creative Commons Attribution (CC BY) license (https:// creativecommons.org/licenses/by/ $4.0 /)$.

\begin{abstract}
The demand for renewable energy resources is invigorated due to various issues primarily related to energy security, energy sustainability, and greenhouse gas emissions. The proper utilization of renewable energy resources has certain challenges due to the varying nature of meteorological parameters and atmospheric aerosols. Therefore, it is of utmost importance to extract the maximum power from the photovoltaic systems with the help of proficient converters. Here, a coupled inductor based highly efficient synchronous interleaved boost converter is designed and developed for the grid integrated photovoltaic system. The proposed converter contains an Insulated Gate Bipolar Transistor (IGBT) switch in place of the conventional diode to maintain zero leakage current, bared minimum switching losses, and improved conduction time thereby enhancing the overall efficiency and reliability of the system. In addition, the proposed system topology is simple to implement and is capable of controlling power at both the generation as well as the load sides. The results obtained are validated with the help of a laboratory prototype under practical scenarios like varying temperature and solar irradiance. Further, an intelligent technique based on modified particle swarm optimization is utilized to extract the maximum power from the photovoltaic system. Moreover, the power quality indices were monitored and analyzed at the point of common coupling and at the grid level which vets the effectiveness of the proposed topology.
\end{abstract}

Keywords: solar photovoltaic system; sustainable power generation; energy security; converter; renewable energy resources

\section{Introduction}

The enhancement of the power electronics components in various applications of the renewable energy sector leads to the requirement of efficient components or configurations so as to obtain better results. Power electronics components play a vital role in transforming power supply and renewable energy resources-based applications [1]. The selection of the accurate topology plays a vital role in building efficient configuration. The entire effectiveness of the solar photovoltaic (PV) system depends on the tracking of the Maximum Power Point Tracking (MPPT), selecting the efficient DC-DC boost converter, and implementation of the efficient configuration of the inverter with control strategies for the grid connected PV system. Significant work has been done in the field of MPPT for its various types and applications [2-5], its superior or improved versions with high accuracy, and fast-tracking under different environmental conditions [6-8]. In [9], a modified MPPT algorithm for reducing the inter harmonics present while tracking maximum power point is proposed whereas, a new concept called boost MPPT system is based on non-linear dynamics so as to track global MPPT without any additional external circuitry is provided in [10]. 
Equally advanced work has been carried out by researchers on DC-DC boost converters. Some topologies with high efficiency, cost-effective, and high step-up are proposed in [11,12]. A comprehensive review of DC-DC converters topologies based on five major drives and accordingly classifying their area of applications is reported in [13]. A comprehensive analysis of the DC-DC converters is provided in [14,15]. A novel high step-up DC-DC converter is provided in [16]. A comparative study of diverse non-isolated DC-DC boost converters is provided [17]. DC-AC converter or inverter topology is also the key factor for a photovoltaic system. In [18], a review of the various inverter topologies or single-phase systems is provided. Specific investigations on inverter topologies have also been done by many researchers. Few of them include multilevel inverter topology [19], transformer-less type inverter topology [20], enhanced z-source [21], and online variable topology [22]. The paper [23] provides the recent trends in inverter topologies. In [24], the disturbance control strategy for LCL filter type grid-connected inverters is focused. The performance of the proposed control method was compared with other conventional control techniques for proving its effectiveness and stability. The matter of fact is that the advancement and researches done with respect to MPPT, DC-DC converters, and DC-AC converters are substantial and grooming with day-to-day advancement in technology. Researchers are focusing on cost-effective, efficient, reliable, and sustainable topology so as to get the most power at the least cost. However, issues pertaining to grid integration, like power quality, also need to be addressed for maintaining a stable and secure system. The power quality responses of grids under usual and unusual conditions with grid-connected solar water pumps have been analyzed [25]. In the paper [26], the power quality issues at the distribution grid after integration of roof-top solar PV system are presented. The recent developments in the grid-connected solar PV system are highlighted [27]. A detailed review of the topologies available in the literature is provided [28]. In the paper [29], emphasis is given to the recent integration requirements related to power quality (PQ) issues. The paper also proposed the control for mitigating PQ concerns whereas the paper [30] discussed the design of fuzzy based space vector PWM controller for mitigations of the power quality issues in the grid connected converters.After reviewing the existing research, some limitations were observed in the area of loss minimization on the DC side and ripple reduction at the DC link capacitor. Also, many researchers have used additional power control devices such as UPQC, DSTATCOM, etc., which enhance the additional cost of the system. Controlling the power on the DC side can enhance the conversion efficiency and thereby reduce the DC ripples present at the DC link capacitor.

The present paper emphasizes the efficient topology of the DC-DC converter so that the maximum power loss can be controlled and maximum efficiency can be obtained on the DC side with reduced ripples present at the input of the inverter. A synchronous interleaved boost converter was developed and presented in this paper. Efforts were made to develop the prototype in the laboratory and test it for the grid integrated solar PV system. Among the various intelligent controllers, the PSO based MPPT controller and the synchronous frame reference (SRF) based phased lock loop (PLL) control strategy for grid synchronization and control were used in this paper. The key objectives of this proposed configuration are as follows:

- This proposed synchronous interleaved boost converter has a switch in place of the diode in the conventional method, which reduced the switching losses across the diode and thus making a more reliable system as compared to the conventional type of interleaved boost converter available.

- This system topology is simple to implement and is capable of controlling power on both sides, that is, on the generation side as well as on the load side. On the generation side, the optimum power was tracked using PSO-based MPPT and then the DC link losses were reduced by using switches in place of diode whereas maintaining the power quality, power factor, and power management on the load side makes the system robust and practical. 
- In case of deviation in the load condition or deviation in the generation side due to solar irradiance, the proposed configuration coordinates with the power generation through the solar PV system and accordingly feeds continuous accessible power to the load to maintain the stability of the system. However, if any deficiency of power occurred from the solar PV system, the same shall be fulfilled by the existing grid power.

The response of grid and total harmonics distortion present in the grid after integration of the proposed system is also recorded in this paper.

The paper is organized as follows: Section 1 describes the Introduction which includes proposed DC-DC boost converter and its advantages over the conventional type boost converter, system configuration and its hardware prototype. Section 2 discusses the results obtained from the proposed system. Section 3 concludes the paper. Authors contribution and references are mentioned thereafter in the paper.

\subsection{Proposed DC-DC Boost Converter}

The basic architecture of the grid integrated solar PV system has mainly three segments which are the DC side, AC side, and DC link as shown in Figure 1. Onthe DC side, the main components are solar PV array and DC-DC converter with MPPT controller; the AC side includes the inverter, filter, and isolation transformer with the AC controller and decoupling capacitor or DC link capacitor, which acts as a link between the DC side and AC side.

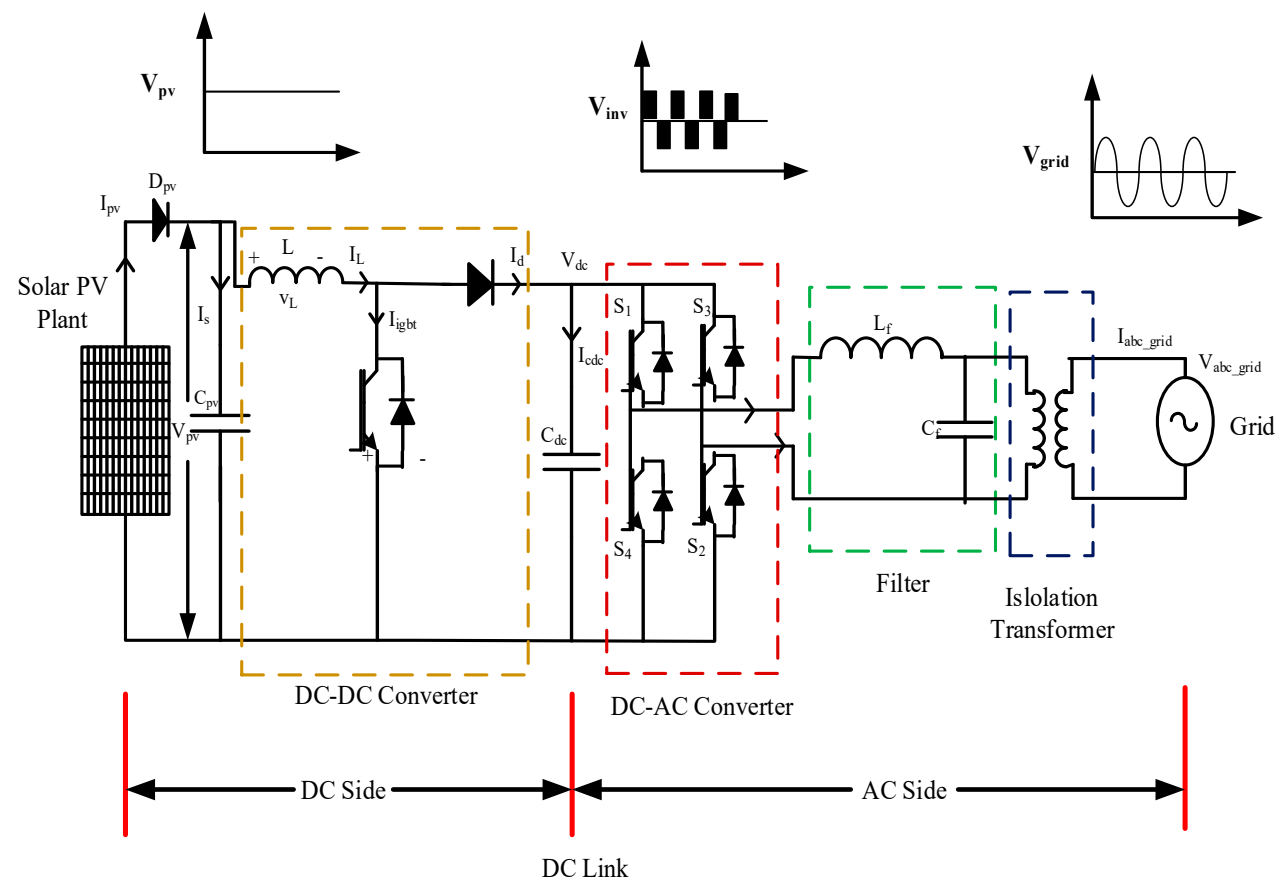

Figure 1. Basic architecture of DC-DC boost converter in grid integrated solar PV system.

The prime focus was given to the DC part of the architecture in this paper. Hence, emphasis was given to the MPPT controller for catering to the real-time variation and to the DC-DC converter for reducing losses and maintaining fewer ripples at the DC link capacitor so as to achieve better results on the AC side of the system.

The selection of topology and further choosing its hardware components required for implementing the same to design the DC-DC converter plays a significant part in formulating the dynamic system. The selection is based on various factors like voltage rating, on-state resistance, current flowing, and switching frequency. The culling of the switching device to be used in the DC-DC converter depends on the intercepting voltage, on-state resistance, and switching frequency. MOSFET and IGBT are the most prominent 
components used as a switching device. If the intercept voltage is below $700 \mathrm{~V}$, then it is preferable to use MOSFET because it provides low conduction loss. Above $700 \mathrm{~V}$ voltage level, IGBT is the better choice. The IGBT based control switch was used in this paper.

\subsection{Benefits of Interleave Boost Converter (IBC) over Traditional Boost Converter (TBC)}

A traditional boost converter is one having one IGBT/MOSET switch, a diode, and an inductor placed in the manner shown in Figure 2. The traditional boost converter has the voltage gain represented as:

$$
V_{\text {gain }}=\frac{V_{o}}{V_{d c}}=\frac{1}{1-D}
$$

where, $D$ stands for the duty ratio, and current across inductor $I_{L}$ is given as:

$$
I_{L}=\frac{I_{O}}{1-D}
$$

At duty ratio, $D=0.5$, the current and voltage stress experienced by the diode and IGBT switch is within permissible limits whereas at a high value of duty ratio or high voltage gain, that is, $D>0.7$, the diode conducts for a prolonged time as compared to the desired value and thus causes an enormously high current and voltage stress [31]. Also, the power loss afterward, over the diode, becomes steeply high at such duty ratios. Thus, photovoltaic applications having large voltage gain and involved in high power capabilities do not suit the use of the conventional type boost converter.

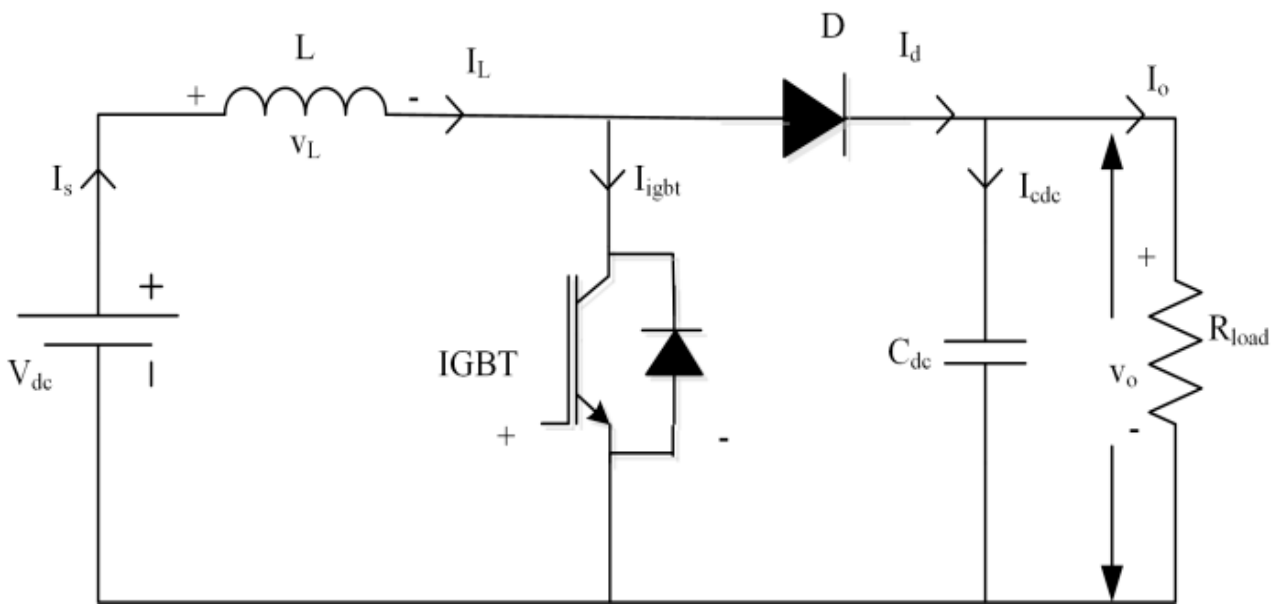

Figure 2. Conventional Boost Converter.

Interleaving the boost convert makes it the special type of boost converter where the current entering into the input gets divided into two paths so as to diminish the conduction losses and hence increases the effectiveness of the scheme.

Figure 3 illustrates the typical boost converter with the interleaved facility where the input current $\left(I_{o}\right)$ is divided into two paths having current $I_{L 1}$ and $I_{L 2}$.

The value of the inductor also gets reduced. The expressions for IBC are:

$$
V_{o}=\frac{V_{d c}}{1-2 D}
$$

where, $D$ is the duty ratio, and inductor current $I_{L}$ is given as:

$$
I_{L}=\frac{I_{O}}{1-2 D}
$$

The proficient ripple frequency at the capacitor's output also improved due to interleaving and thus reduces the ripple voltage conveniently at the converter's output. Also, as compared to the $\mathrm{CBC}$, the IBC is able to handle more power. 


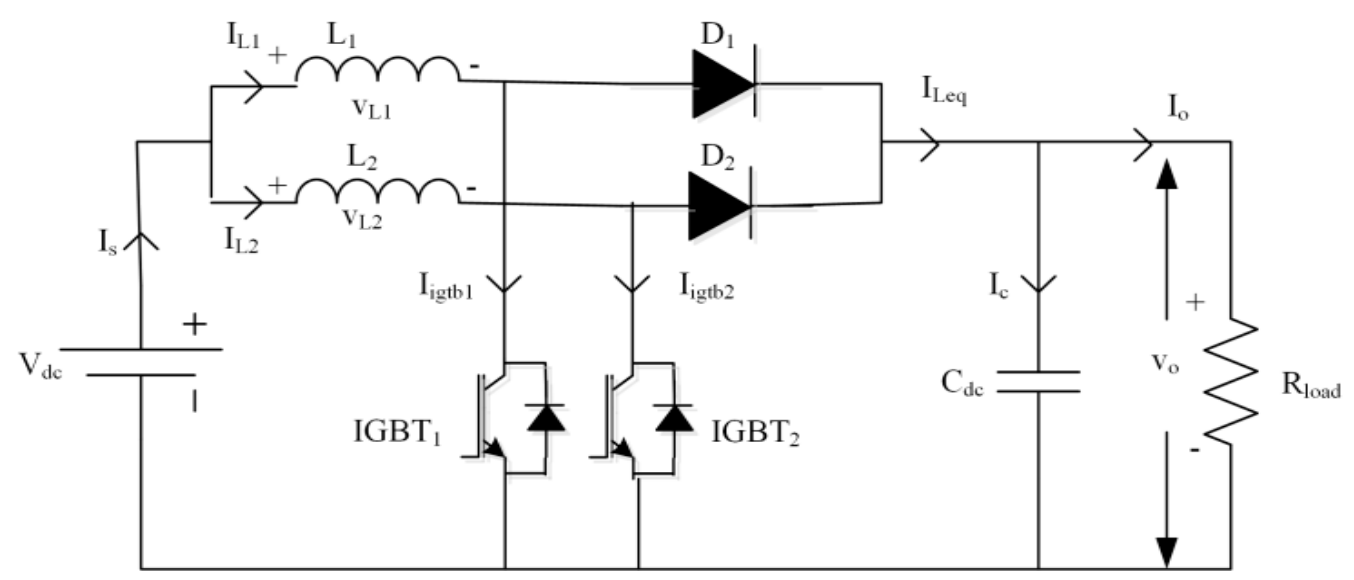

Figure 3. Interleaved Boost Converter.

\subsection{Synchronous and Non-Synchronous Means of Operation}

The fundamental operation of the converter with traditional boosting capabilities and interleaving is usually based on the non-synchronous mode. In the non-synchronous mode of operation, the converter contains the combination of IGBT/MOSFET and diode. However, during the synchronous mode of operation, the diode is substituted by the switch, either IGBT or MOSFET, thereby reducing the losses, and hence the efficiency of the converter gets enhanced. The loss calculations of boost converter under synchronous and non-synchronous mode are analyzed [32]. There are two sources of power loss across IGBT/MOSFET one is power loss across the resistive elements of the MOSFET and the second is the dissipation of power due to the switching losses. Further, the size of MOSFET is conversely proportional to the resistance loss. More is the size of the MOSFET, less will be the resistance loss. This resistance is called on-resistance $\left(R_{o n}\right)$. The second loss is the switching loss. When MOSFET toggles on and off, the inherent freeloading capacitance accumulates and then disperses the energy at each interval. The switching frequency is directly proportional to this loss and thus with the enhancement in the size of the MOSFET, its capacitance also enhances resulting in enhancement of switching loss. The expression for the same is as below:

Power loss across IGBT/MOSFET:

$$
P_{m f}=P_{R o n}+P_{s w}=\left[\left(\frac{D R_{o n}}{(1-D)^{2} R}\right)+\left(\frac{1}{2} f C_{o} R\right)\right] P_{o}
$$

where, $D$ stands for the duty ratio, $R_{\text {on }}$ represents the on-resistance of MOSFET, $f$ denotes the switching frequency, $C_{o}$ represents the capacitance at the output of the MOSFET and $P_{o}$ is the output power and power loss across the diode is given as:

$$
P_{D}=P_{f v}+P_{R f}=\left[\left(\frac{V_{F}}{V_{o}}\right)+\left(\frac{R_{F}}{(1-D) R}\right)\right] P_{o}
$$

where, $V_{F}$ represents the forward voltage drop, $R_{F}$ stands for the forward resistance of the dynamic diode and $V_{o}$ is the output voltage.

Loss across the inductor $\left(P_{L}\right)$ and capacitor $\left(P_{C}\right)$ is given as:

$$
\begin{gathered}
P_{L}=\frac{R_{L}}{(1-D)^{2} R} P_{o} \\
P_{C}=\frac{D R_{C}}{(1-D) R} P_{o}
\end{gathered}
$$


Therefore, as the synchronous mode of operation is adopted, the power loss across the diode as represented in Equation (6) gets replaced by the power loss across the MOSFET as represented in Equation (5) making the synchronous configuration more efficient.

\subsection{Circuit Diagram of Synchronous Interleave Boost Converter}

In the present paper, the boost converter with the interleaved facility is proposed, which is working in the synchronous mode of operation. This synchronous interleaved boost converter (SIBC) has a dual advantage, that is, the advantage of interleaving the input current thereby reducing the losses and second operating in the synchronous mode, that is, by replacing the diode with the IGBT/MOSFET. The circuit design of the prospective model is demonstrated in Figure 4.

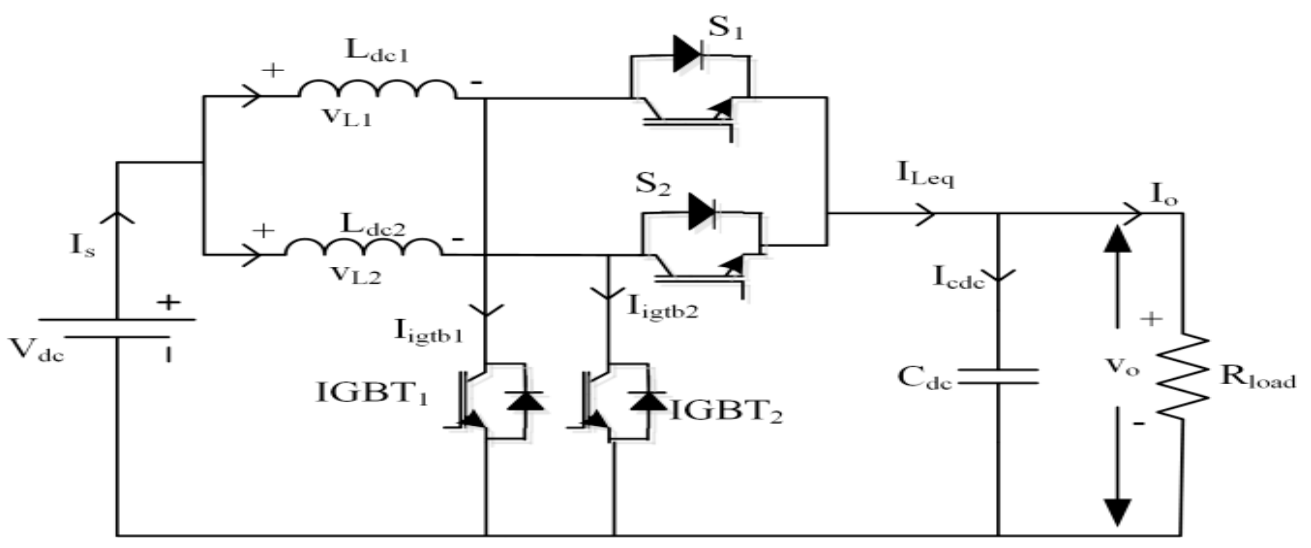

Figure 4. Synchronous Interleaved Boost Converter.

As observed from Figure 4, the two IGBTs and the two diodes were replaced with the two MOSFETs/switches say $S_{1}$ and $S_{2}$. Due to interleaving the inductor $L$ is divided into two parallel inductors having values $\mathrm{L}_{\mathrm{dc} 1}$ and $\mathrm{L}_{\mathrm{dc} 2}$. The output voltage $\left(V_{o}\right)$ and load current $\left(I_{0}\right)$ was derived and is represented as:

$$
\begin{aligned}
& V_{o}=\frac{V_{d c}\left(T+\Delta_{t}\right)}{T(1-2 D)+\left(\Delta_{t}\right)} \\
& I_{o}=\frac{I_{o}\left(T+\Delta_{t}\right)}{T(1-2 D)+\left(\Delta_{t}\right)}
\end{aligned}
$$

where, $T$ is the total duration of time the converter is conducting and $\Delta_{t}$ is the incremental time of conduction.

\subsection{System Configuration and Hardware Setup}

The configuration of the synchronous boost converter-based grid connected solar PV system is shown in Figure 5. The system consists of the $1.5 \mathrm{~kW}$ grid integrated solar PV system, a highly efficient synchronous interleaved boost converter having two shunt connected inductors having a value of $2.3 \mathrm{mH}$, input capacitance of $470 \mu \mathrm{F}$ each, and output capacitance of $1200 \mu \mathrm{F}$. The diodes were replaced with the IGBT based switches, which are denoted as $S_{1}$ and $S_{2}$ respectively. The three-stack voltage source converter having three IGBTs branches containing two switch ports was connected with the boost converter with the DC link capacitance having a value of $1200 \mu \mathrm{F}$. 


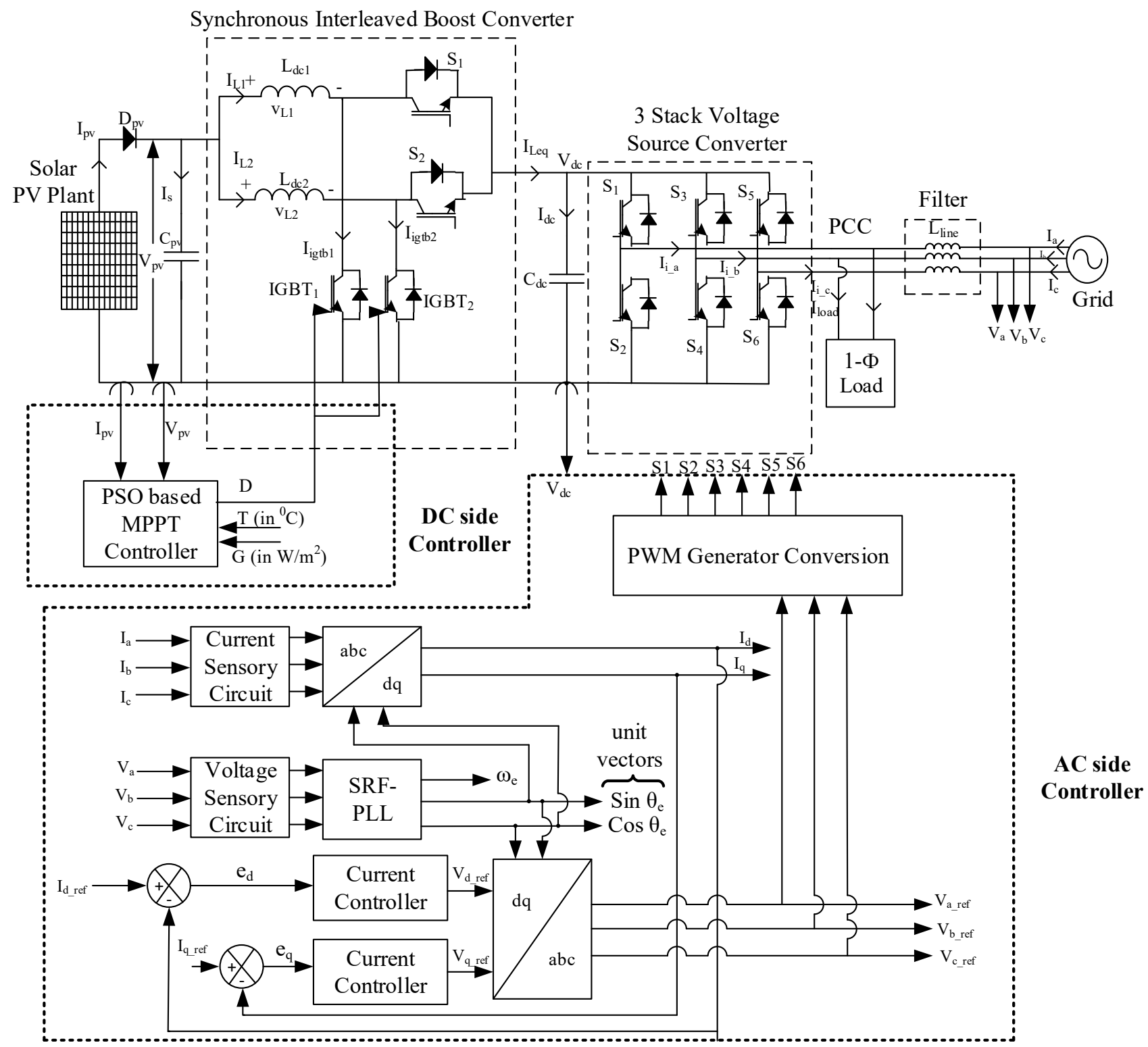

Figure 5. Architecture of grid integrated solar PV system.

The technique used for tracking the maximum power point in the proposed configuration is particle swarm optimization (PSO), which is used to generate pulses and regulate the switches of the boost converter. The PSO was selected due to its faster response in case of the partial shading conditions of PV modules. The typical PSO method may be described using the following equations:

$$
\begin{gathered}
v_{i(k+1)}=w(k) v_{i}(k)+c_{1} r_{1}\left(l_{\text {best }}-x_{i}(k)\right)+c_{2} r_{2}\left(g_{\text {best }}-x_{i}(k)\right) \\
x_{i}(k+1)=x_{i}(k)+v_{i}(k+1)
\end{gathered}
$$

This algorithm is an intuitive method that is used for optimization by calculating the fitness function and then continuously amending the local best (LB) and global best (GB) points thus assuring the chasing of global maxima if the situation of partial shading conditions persists.

The AC side controller also plays a vital role in grid synchronism. The foremost requirement for grid synchronism is to measure the grid voltage $\left(\mathrm{V}_{\text {grid }}\right)$, phase angle $(\Phi)$, and frequency (f) and match with the voltage, phase angle, and frequency of the inverter output respectively. In this paper, the phase lock loop (PLL) based method has been used 
due to its advantage of well-established and simple configuration to implement. The synchronous reference frame phase lock loop (SRF-PLL) used for the control at the AC side is shown in Figure 6. The SRF-PLL determines the phase and frequency of the grid voltage. The outputs of the SRF-PLL are the sine and cosine signals with unit magnitude. These are known as the unit vectors and are utilized to produce reference signals. The SRF-PLL is capable of handling disturbances like DC offset, unbalance, and harmonics.

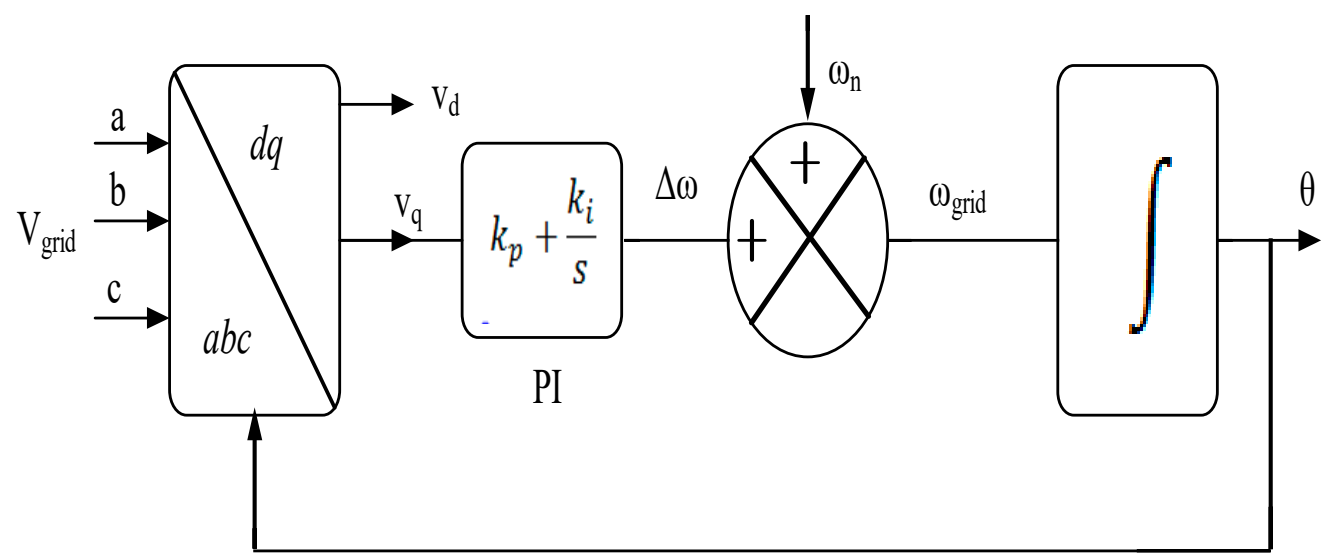

Figure 6. Basic synchronous reference frame phase lock loop (SRF-PLL).

The hardware prototype was developed wherein the control was provided with the help of a dSPACE DSP board 1104 [33], which is used as an interface between the hardware components and the computer-based algorithms for control strategies. The complete hardware setup is illustrated in Figure 7.

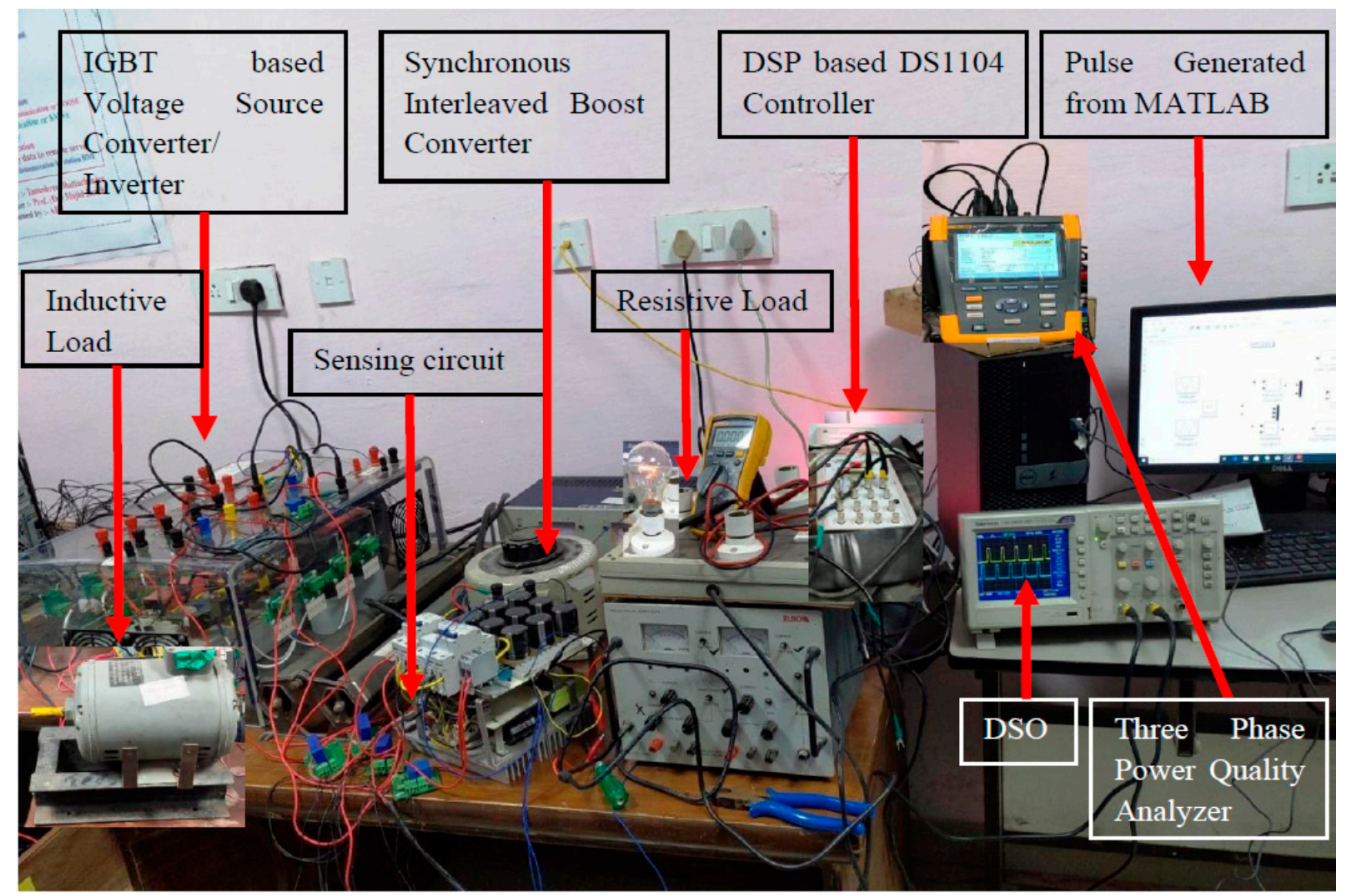

Figure 7. Hardware laboratory prototype of the proposed research.

The hardware archetype of the synchronous interleaved boost converter was established after theoretical study and carrying out the simulation and the replica of the same is demonstrated in Figure 8. 


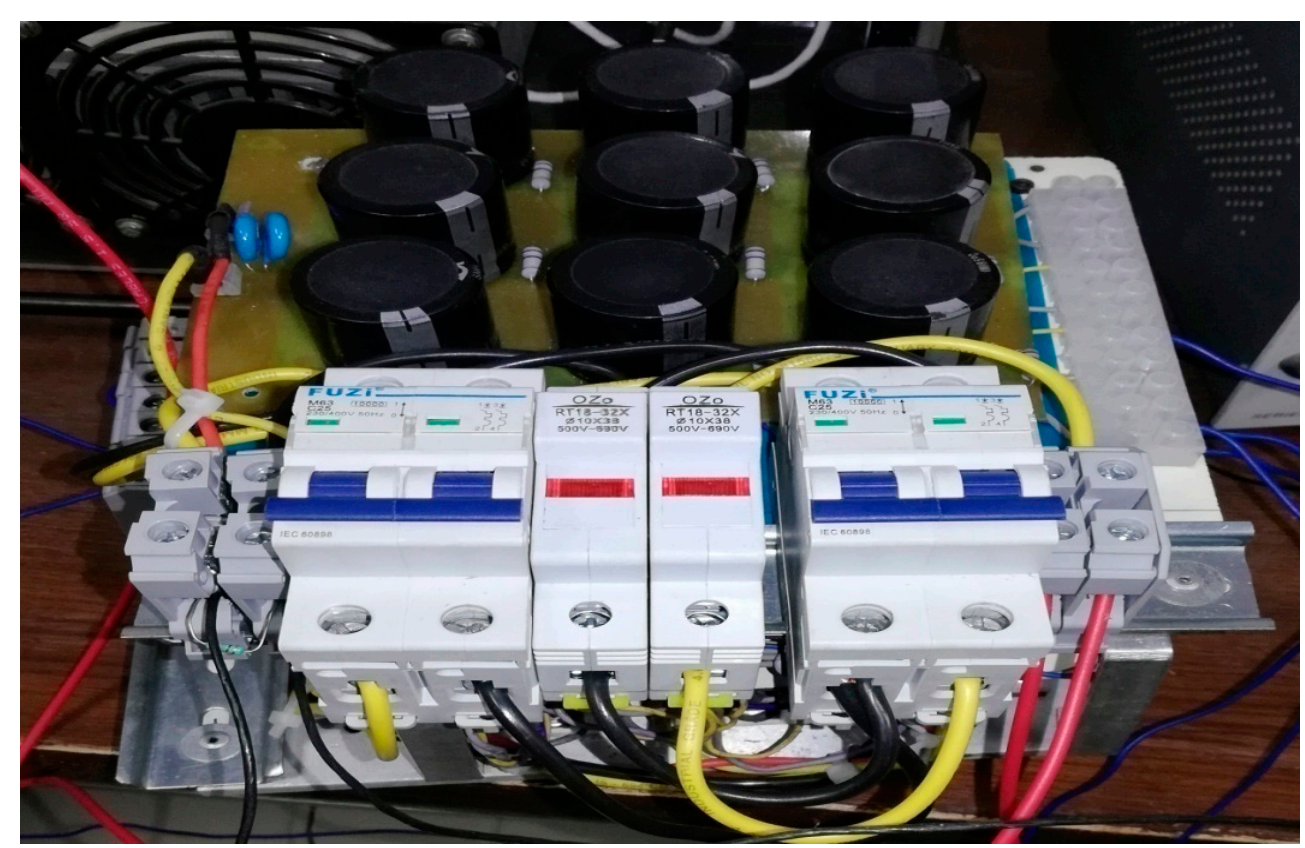

Figure 8. Hardware replica of synchronous interleaved boost converter.

The hardware of the synchronous interleaved boost converter consists of the two-leg IGBT, DC link capacitor, input capacitor, HRC fuses for protection, and input inductor. The rating of the same is given in Table 1.

Table 1. Hardware Components Parameters.

\begin{tabular}{cccc}
\hline S. No. & Description of the Item & Qnty. & Specification \\
\hline 1. & Two-leg IGBT & 2 Nos. & SKM100GB12T4, 1200 V, 100 A \\
2. & DC Link Capacitor & 1 No. & $1200 \mu \mathrm{F}, 500 \mathrm{~V} .100 \mathrm{k} \Omega$ resistor is \\
3. & Interleaved Inductor & 2 Nos. & connected across capacitor. \\
4. & HRC fuse & 2 Nos. & $500 \mathrm{~V}, 100 \mathrm{kA}, 10 \times 38$, IEC269 \\
5. & Input Capacitor & 1 No. & $470 \mu \mathrm{F}$ \\
\hline
\end{tabular}

For sensing the current and voltage of the PV system and the grid, the sensory circuit was designed. This sensory circuit shall sense the actual value of the current and voltage and feed to the computer-based controller through dSPACE 1104.

The current is sensed using the sensor, LEM LA $25 \mathrm{P}$ and the voltage through the sensor, LEM LV 25 P.

The three-phase, $10 \mathrm{kVA}, 415 \mathrm{~V} \mathrm{AC}, 50 \mathrm{~Hz}$, with a switching frequency capability of up to $20 \mathrm{kHz}$, three-stack voltage source converter was designed for the proposed configuration. The proposed voltage source converter can cater the DC voltage range from $200 \mathrm{~V}$ to $800 \mathrm{~V}$. The Semikron make SKM100GB12T4 IGBT having a pair of switches was used as one leg and four such legs were configured, one for each phase R, Y, and B, and one leg spare for either grounding purposes or as a standby. The Semikron IGBT driver circuit was used for driving the IGBT. The hardware realization of the voltage source converter is shown in Figure 9. 


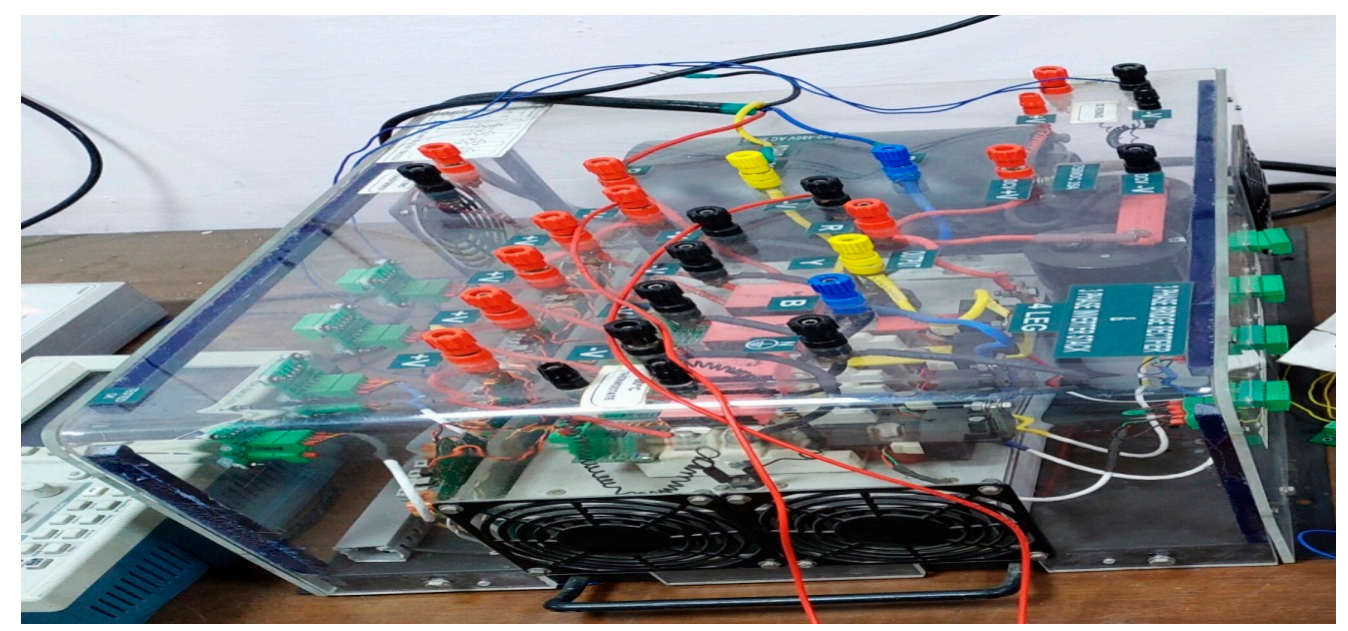

Figure 9. Hardware realization of voltage source converter.

\section{Results and Discussions}

The $100 \mathrm{kWp}$ solar PV system was designed and simulated with a solar PV module of rating $305 \mathrm{Wp}$ each. A total of five modules were linked in sequence and 66 such strings were connected in shunt to form an array. A total of five modules were linked in sequence and 66 such strings were connected in a shunt to form an array. The variation of irradiance and temperature was considered under this study for vetting the response of the proposed system under different environmental uncertainties.

For analysis, the same, the $1.5 \mathrm{~kW}$ hardware archetype was established in the research lab. The DS1104 DSP board was based on a 64-bit PowerPC type PPC603e processor. The board included analog to digital (A/D), digital to analog (D/A) converters, and digital incremental encoder interfaces. The controller was designed using MATLAB Simulink and the pulses generated were provided to fire the IGBTs in the hardware setup using dSPACE Control Desk software [33]. The controlling of the firing angle and other controls was done using dSPACE graphical user interface GUI software. With this GUI, it was possible to see the real-time output and any changes in the controller could be observed on a real-time basis. The pulses given to the IGBTs of the synchronous boost converter are shown in Figure 10, whereas the $1.5 \mathrm{~kW}$ solar PV modules installed on a roof top were used for providing DC power to the proposed prototype, which is illustrated in Figure 11.

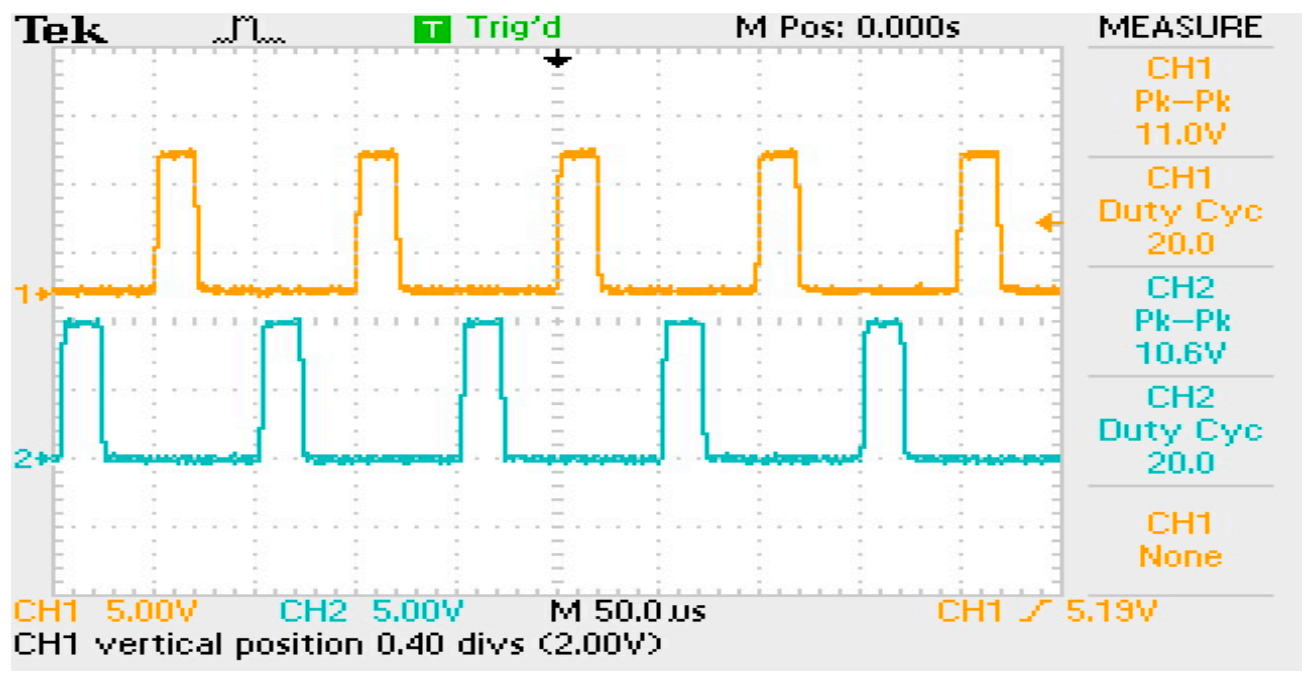

Figure 10. Pulse output from dSPACE 1104. 


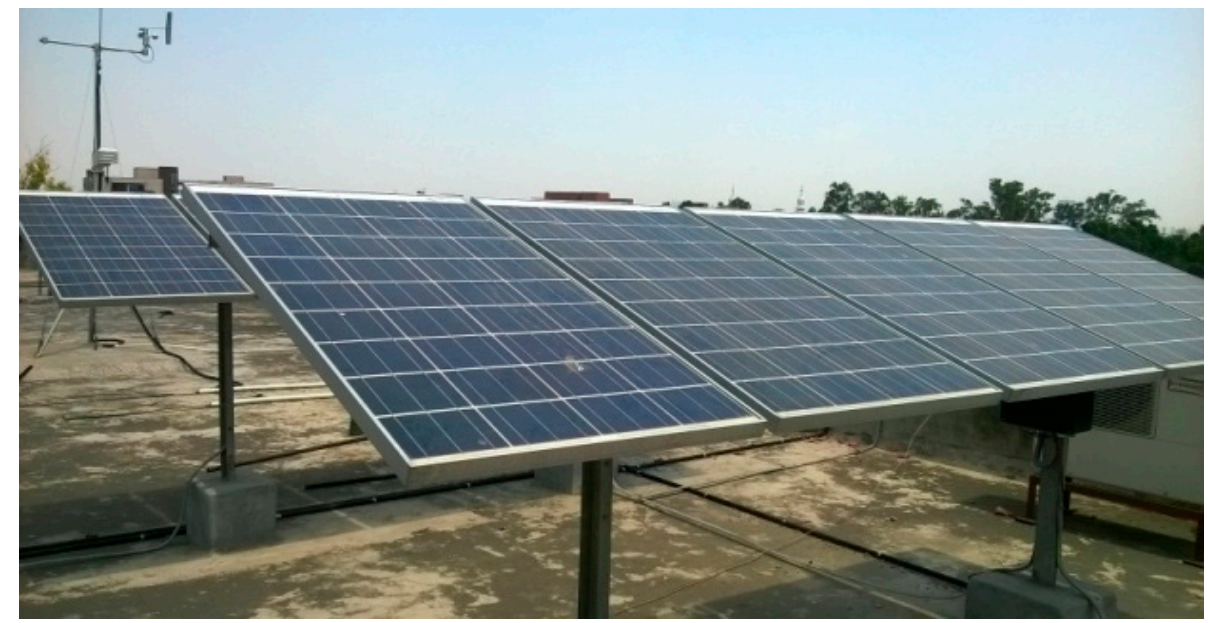

Figure 11. Solar PV modules.

The magnitude of irradiance considered was $1000 \mathrm{~W} / \mathrm{m}^{2}$ initially and it varied over the time period. The simulation was done for $2.5 \mathrm{~s}$. At time $\mathrm{t}=0.6 \mathrm{~s}$, the irradiance varied to the level of $200 \mathrm{~W} / \mathrm{m}^{2}$ and then started rising to attain the value of $1000 \mathrm{~W} / \mathrm{m}^{2}$ at time $t=1.7 \mathrm{~s}$. Then, to vet the variation of the temperature, the temperature was initially considered as $25^{\circ} \mathrm{C}$ till $\mathrm{t}=2 \mathrm{~s}$. After $2 \mathrm{~s}$, the temperature rose to $50{ }^{\circ} \mathrm{C}$. Figure 12 depicts the responses received from the photovoltaic system under different environmental conditions.
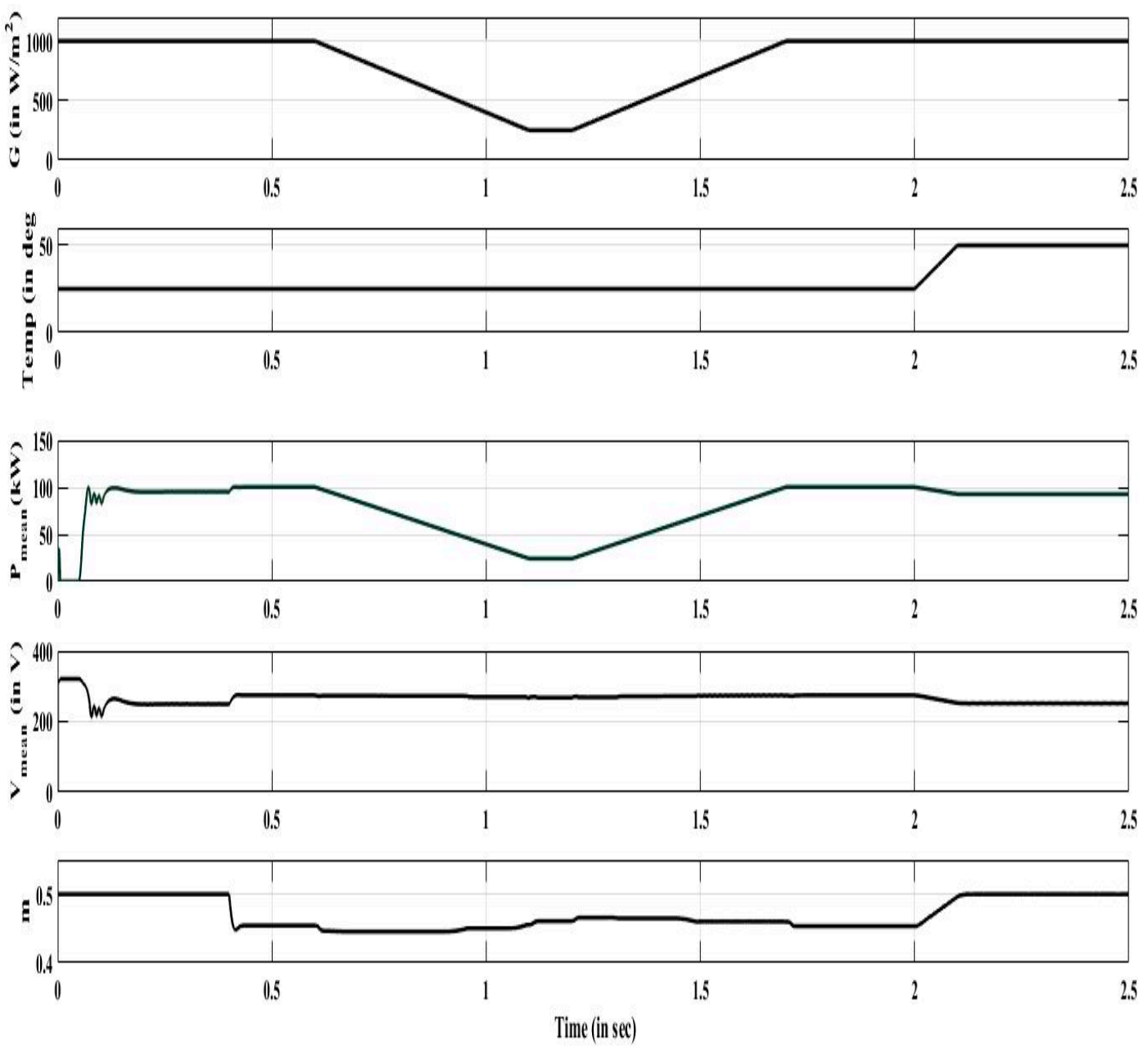

Figure 12. Response of the solar PV system under varying environmental conditions. 
It was observed that as the irradiance value dipped, the corresponding voltage and power also dropped in the same respect, which shows the direct relationship between the irradiance and voltage. However, with the increase in temperature, the voltage and power reduced, which illustrates the inverse relationship between the temperature and voltage till the standard temperature condition (STC) of the PV module.

The synchronous interleaved boost converter configuration was implemented for this grid tied solar PV system. For verifying the reliability and robustness of the proposed system, a comparative analysis of the synchronous mode of operation and non-synchronous conventional type of boost converter was carried out. The simulation results obtained are shown in Figure 13. The response in black color denotes the non-synchronous mode whereas the response obtained in magenta color is the proposed synchronous mode of operation. The response clearly depicts the stability and efficient regulation of the ripples of the output voltage waveform from the synchronous mode of operation as compared to the non-synchronous mode.

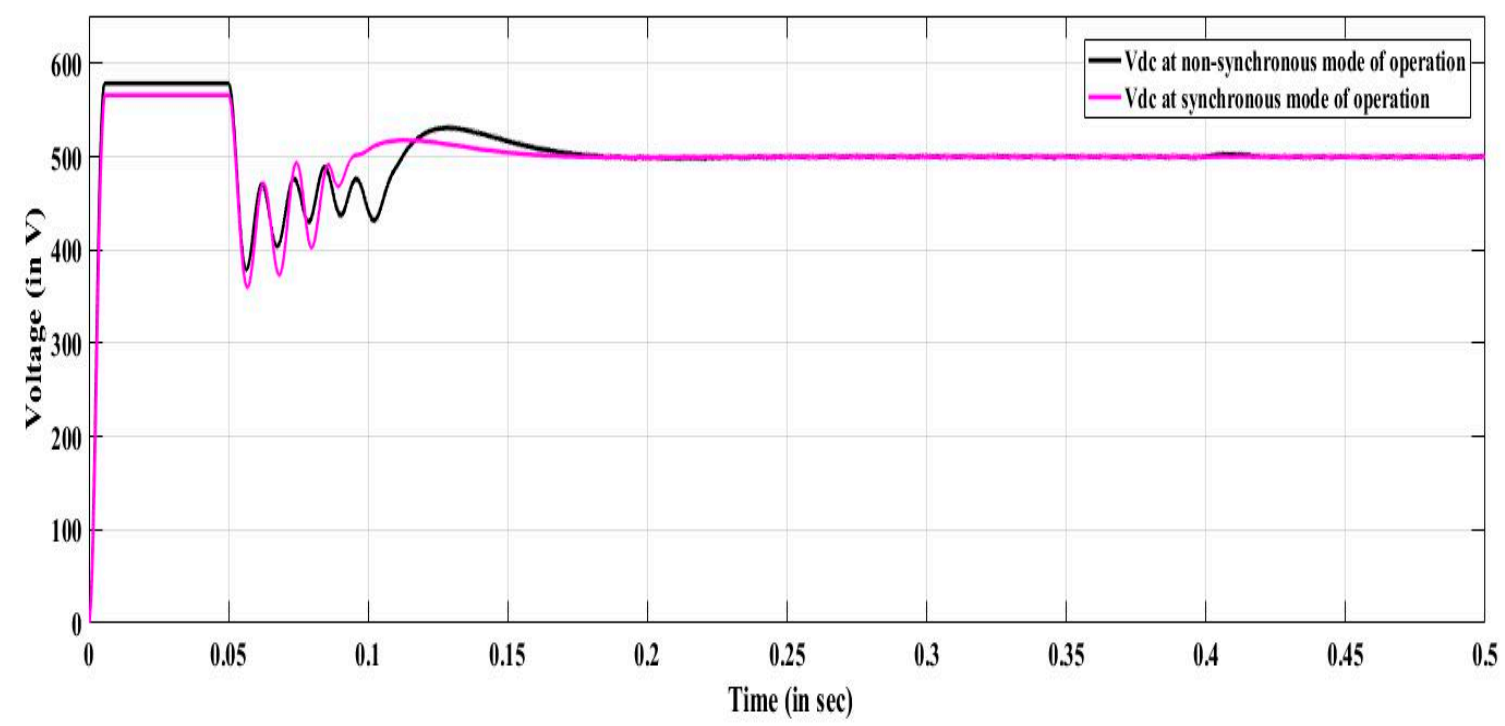

Figure 13. Synchronous vs. non-synchronous mode of operation for boost converter.

The simulation results illustrate the presence of fewer ripples in voltage for the DC link capacitor when functioning in the synchronous mode of operation and it is stabled in early time with stable voltage. Also, the average magnitude of the DC voltage measured is greater in the case of the synchronous mode of operation as compared to the nonsynchronous boost converter. The voltage at the output of the voltage source converter is after the DC link capacitor was measured and is shown in Figure 14.

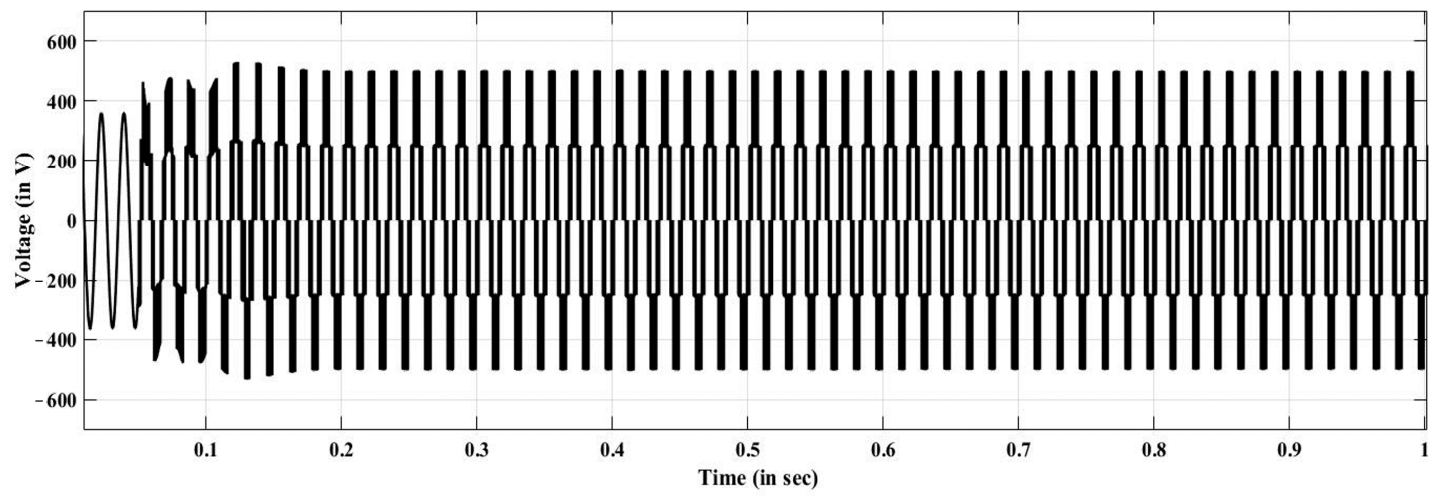

Figure 14. Voltage profile at the output of VSC. 
It was observed that the conversion efficiency of the proposed converter configuration was recorded to be more than $93 \%$ under different duty ratios. To synchronize the output response received through voltage source converter with the power grid, the synchronous reference frame phase lock loop-based AC control scheme with PI controller was implemented. The complete AC control scheme is demonstrated in Figure 15.

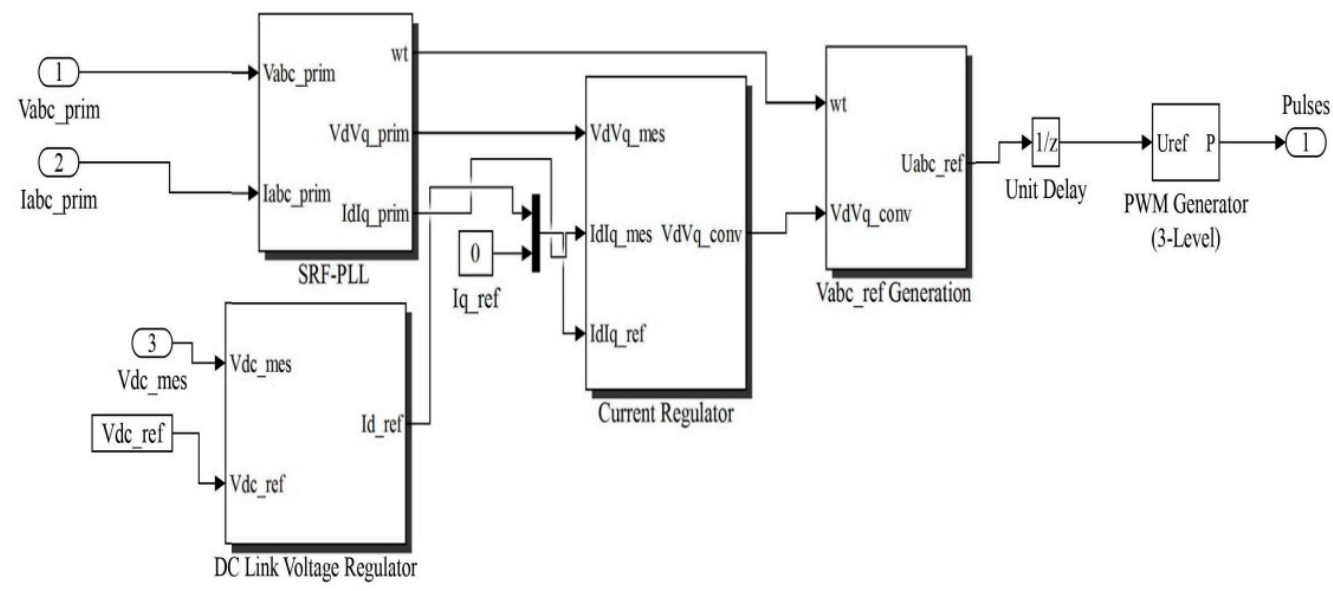

Figure 15. AC side controller.

The sensory circuit senses the three-phase voltages $\left(\mathrm{V}_{\mathrm{a}}, \mathrm{V}_{\mathrm{b}}\right.$, and $\left.\mathrm{V}_{\mathrm{c}}\right)$ and currents $\left(\mathrm{I}_{\mathrm{a}}, \mathrm{I}_{\mathrm{b}}\right.$, and $\left.\mathrm{I}_{\mathrm{c}}\right)$ from the grid and fed into the control scheme. Then these three-phase voltage signals are converted into the two-phase stationary frame using abc to $\alpha \beta$ transform using Equation (13).

$$
\left[\begin{array}{l}
\mathrm{V}_{\alpha} \\
\mathrm{V}_{\beta}
\end{array}\right]=\left[\begin{array}{ccc}
\frac{2}{3} & -\frac{1}{3} & -\frac{1}{3} \\
0 & \frac{1}{\sqrt{3}} & -\frac{1}{\sqrt{3}}
\end{array}\right]\left[\begin{array}{l}
\mathrm{V}_{\mathrm{a}} \\
\mathrm{V}_{\mathrm{b}} \\
\mathrm{V}_{\mathrm{c}}
\end{array}\right]
$$

Then these stationary frame values $V \alpha$ and $V \beta$ transform into the rotating reference frame. This conversion is called $\alpha \beta$ to dq transformation. This is carried out using Equation (14).

$$
\left[\begin{array}{c}
\mathrm{V}_{\mathrm{d}} \\
\mathrm{V}_{\mathrm{q}}
\end{array}\right]=\left[\begin{array}{cc}
\cos \theta_{\mathrm{e}} & \sin \theta_{\mathrm{e}} \\
-\sin \theta_{\mathrm{e}} & \cos \theta_{\mathrm{e}}
\end{array}\right]\left[\begin{array}{c}
\mathrm{V}_{\alpha} \\
\mathrm{V}_{\beta}
\end{array}\right]
$$

where $\theta_{\mathrm{e}}$ is the estimated angle calculated from the synchronous reference frame-based phase lock loop. The PI controller is used in association with the PLL so that the value of $\mathrm{V}_{\mathrm{d}}$ is terminated or zero at steady state and the grid voltage is preferably aligned with the q-axis of the rotating reference frame. After the process of PLL, the outcome received is the estimated frequency, which is represented here as $\omega_{\mathrm{e}}$ and estimated angle $\theta_{\mathrm{e}}$. This estimated angle is multiplied with the sine and cosine factor to generate unit vectors $\operatorname{Sin} \theta_{\mathrm{e}}$ and $\cos \theta_{\mathrm{e}}$ respectively.

The system acts as nonlinear due to the rotating reference frame which is transformed from the stationary reference frame. The value of $V_{d}$ is calculated using Equation (14) and is given as:

$$
\mathrm{V}_{\mathrm{d}}=\mathrm{V}_{\alpha} \cos \theta_{\mathrm{e}}+\mathrm{V}_{\beta} \sin \theta_{\mathrm{e}}
$$

Differentiate Equation (15) with respect to $\theta_{\mathrm{e}}$

$$
\frac{d V_{d}}{d \theta_{e}}=-V_{\alpha} \omega_{e} \sin \theta_{e}+\frac{d V_{\alpha}}{d \theta_{e}} \cos \theta_{e}+V_{\beta} \omega_{e} \cos \theta_{e}+\frac{d V_{\beta}}{d \theta_{e}} \sin \theta_{e}
$$

The estimated frequency is given by:

$$
\omega_{\mathrm{e}}=-\mathrm{K}_{\mathrm{p}} \mathrm{V}_{\mathrm{d}}-\mathrm{K}_{\mathrm{i}} \int \mathrm{V}_{\mathrm{d}} \mathrm{dt}+\mathrm{C}
$$




$$
\begin{gathered}
\frac{\mathrm{d} \omega_{\mathrm{e}}}{\mathrm{d} \theta_{\mathrm{e}}}=-\mathrm{K}_{\mathrm{p}} \frac{\mathrm{d} \mathrm{V}_{\mathrm{d}}}{\mathrm{d} \theta_{\mathrm{e}}}-\mathrm{K}_{\mathrm{i}} \mathrm{V}_{\mathrm{d}} \\
\frac{\mathrm{d} \omega_{\mathrm{e}}}{\mathrm{d} \theta_{\mathrm{e}}}=\mathrm{P}_{1} \cos \theta_{\mathrm{e}}+\mathrm{P}_{2} \sin \theta_{\mathrm{e}}
\end{gathered}
$$

where,

$$
\begin{aligned}
& P_{1}=-K_{p} \frac{d V_{\alpha}}{d \theta_{e}}-K_{p} V_{\beta} \omega_{e}-K_{i} V_{\alpha} \\
& P_{2}=-K_{p} \frac{d V_{\beta}}{d \theta_{e}}-K_{p} V_{\alpha} \omega_{e}-K_{i} V_{\beta}
\end{aligned}
$$

Equation (19) is a nonlinear equation. $V_{\alpha}$ and $V_{\beta}$ are quadrature signals wherein $V_{\beta}$ lags $90^{\circ}$ with respect to $V_{\alpha}$. The $\mathrm{I}_{\mathrm{d}_{-} \text {ref }}$ is generated by comparing the actual assessment of voltage at $\mathrm{DC}$ link $\left(\mathrm{V}_{\mathrm{dc}}\right)$ and reference value $\mathrm{V}_{\mathrm{dc} \_ \text {ref }}$ in $\mathrm{DC}$ link controller whereas $\mathrm{I}_{\mathrm{q} \_ \text {ref }}$ is generated by evaluating the reference value reactive power in the grid using a $\mathrm{Q}$ controller based on the dips present in the grid and then this reference value is given to the inner current loop to generate the same.

Figure 16 displays the voltage and current profile at the output of the grid integrated solar PV inverter. Figure 17 is the voltage and current profile of the grid where the voltage level at the grid side is considered at the primary distribution system, which is at $20 \mathrm{kV}$ voltage level which can be stepped down with the help of a distributed transformer for further integration into the distribution side and consumer load.
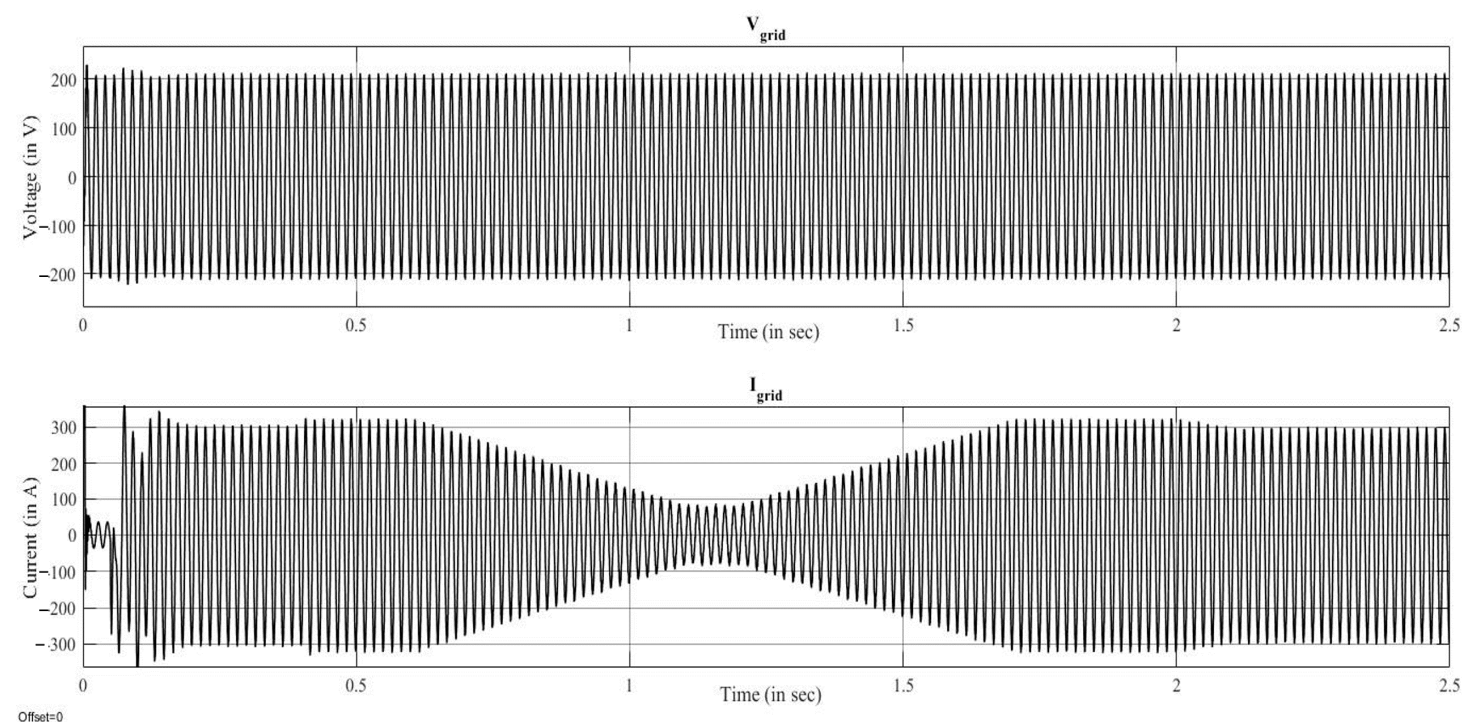

Figure 16. Voltage and current profile at the output of the grid tied VSC.
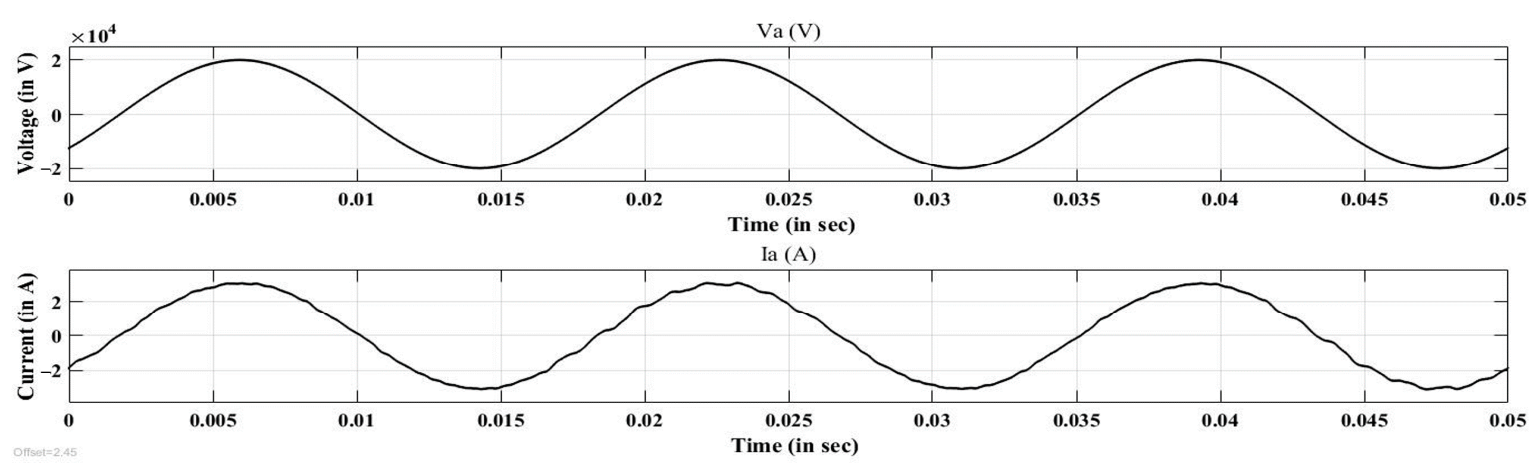

Figure 17. Voltage and current profile at the grid side.

The voltage and current at inverter output and point of common coupling of the distributed network was recorded using Fluke Energy and Power meter and is illustrated in Figures 18 and 19 respectively. 

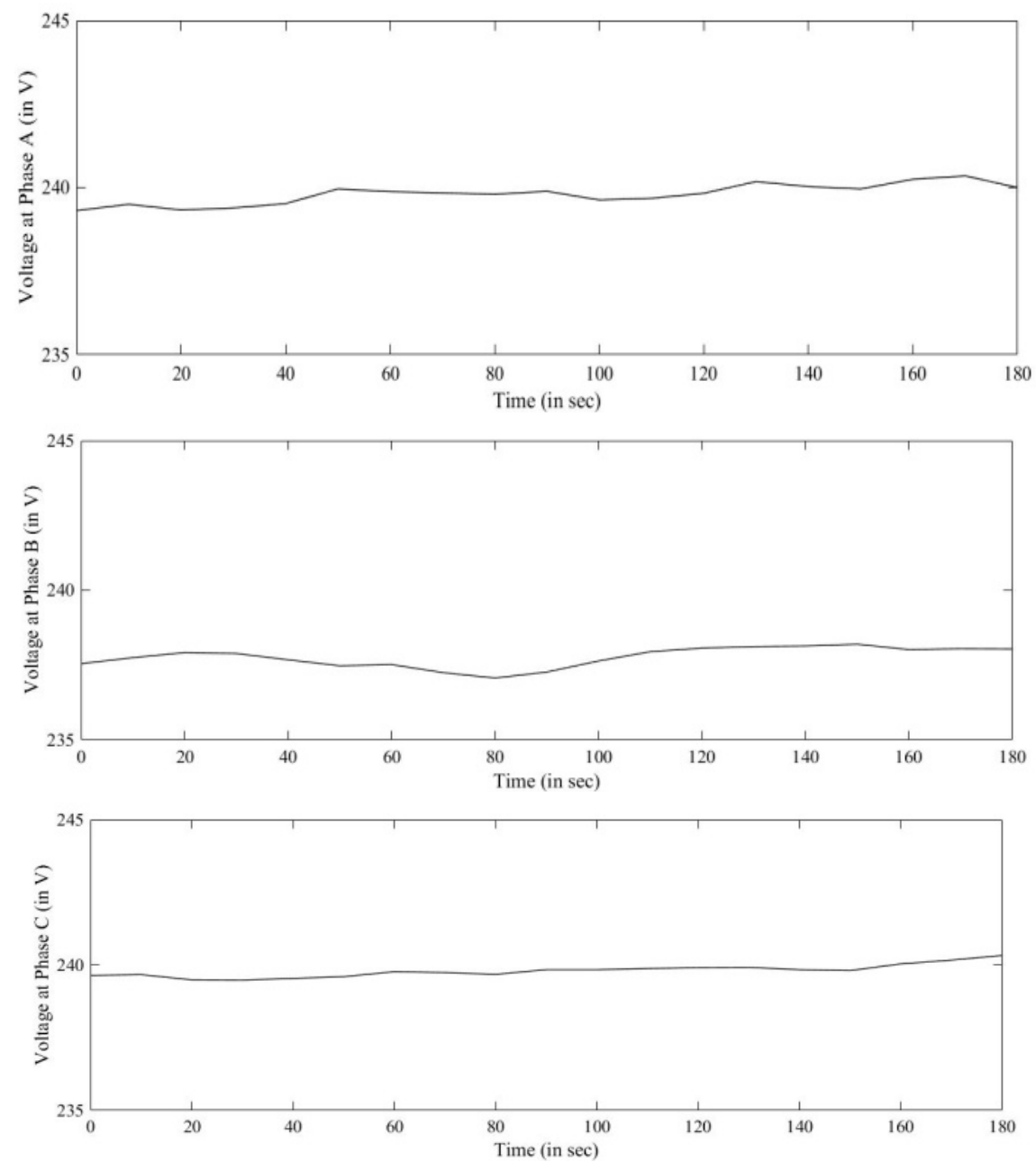

(a)
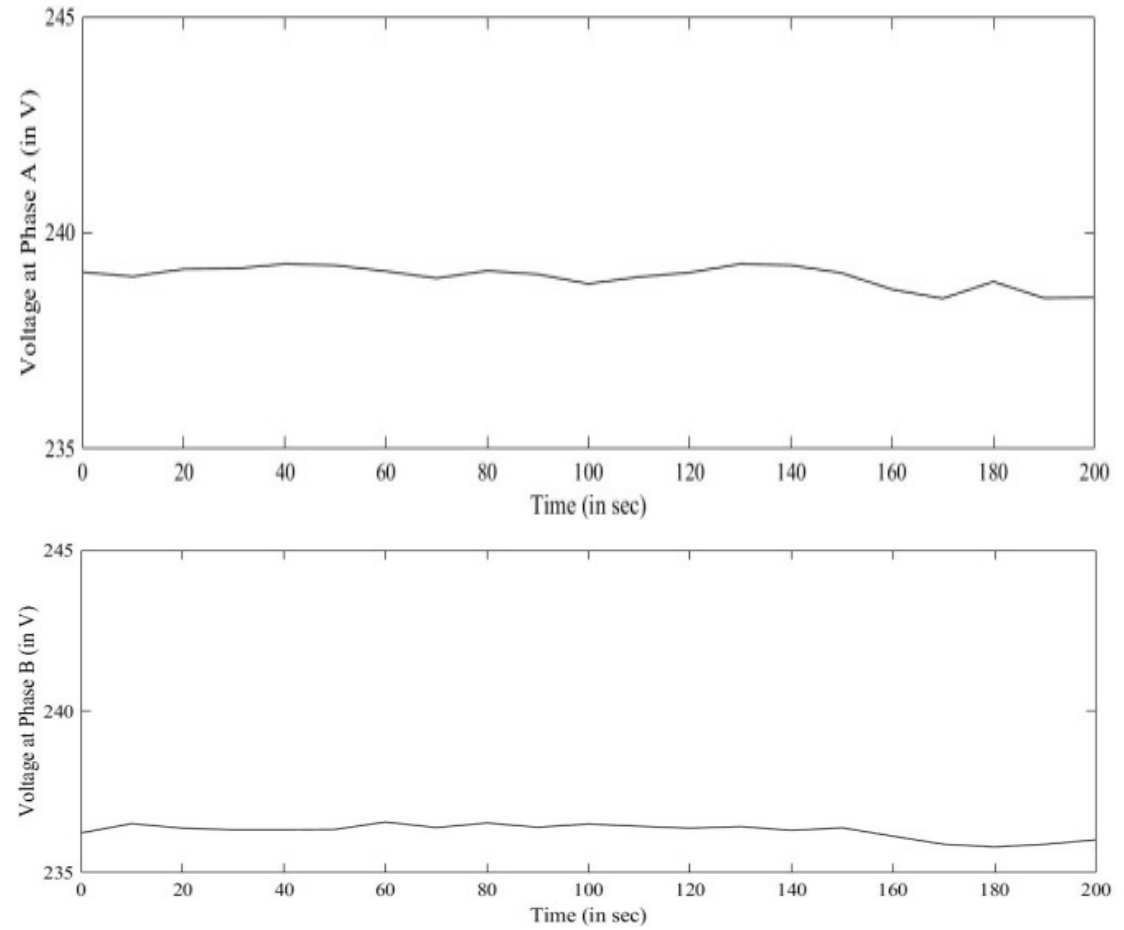

Figure 18. Cont. 


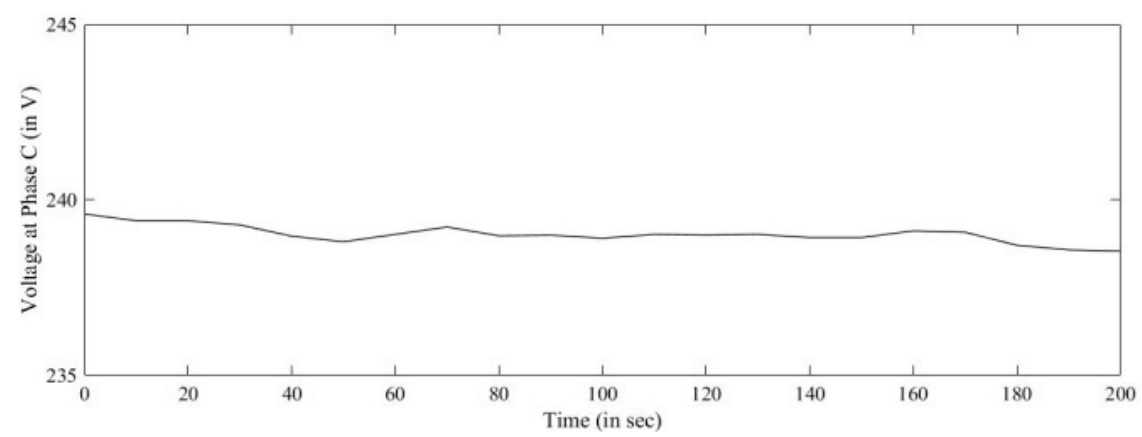

(b)

Figure 18. Voltage waveform of (a) output of inverter (b) at PCC.
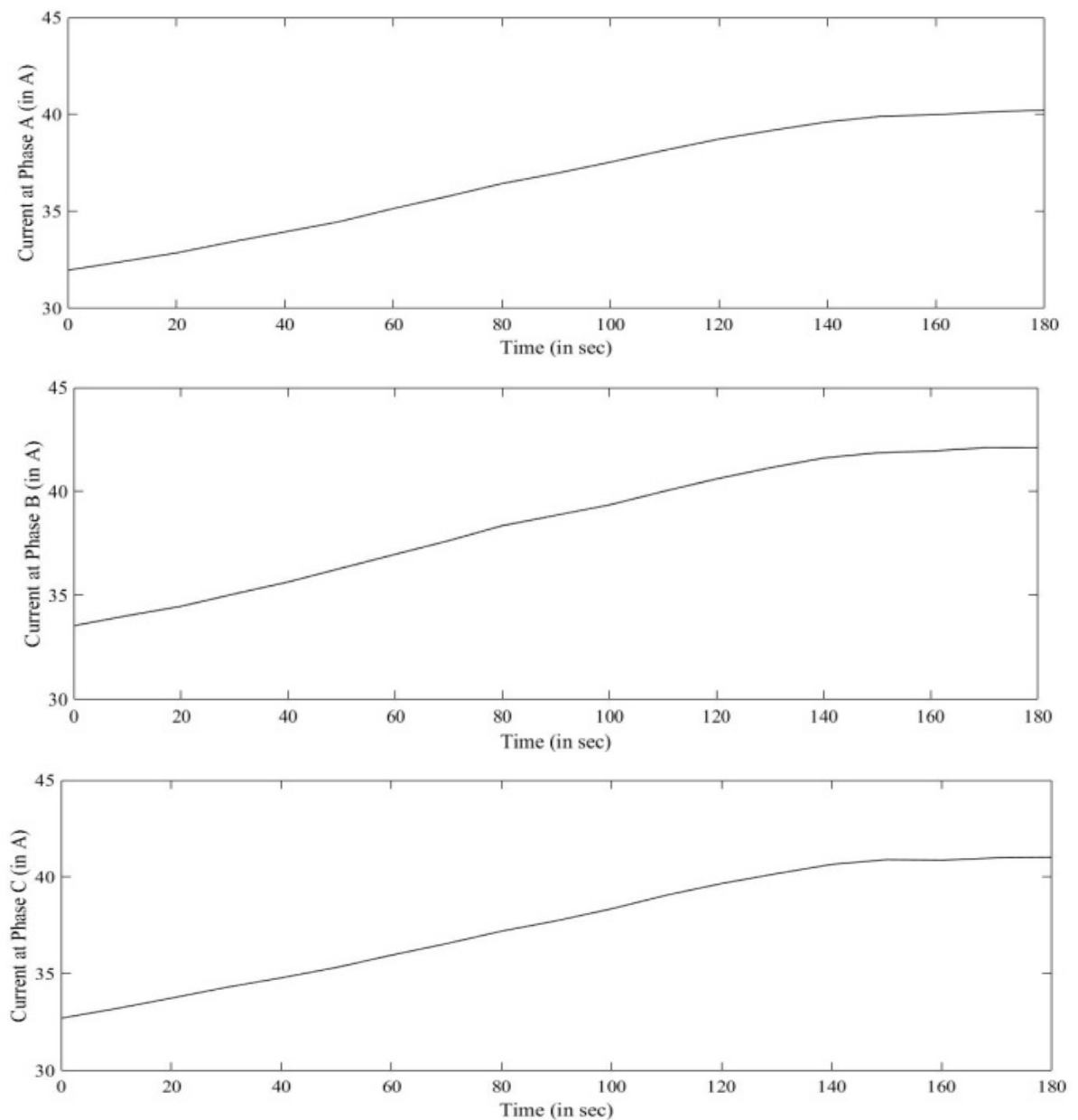

(a)

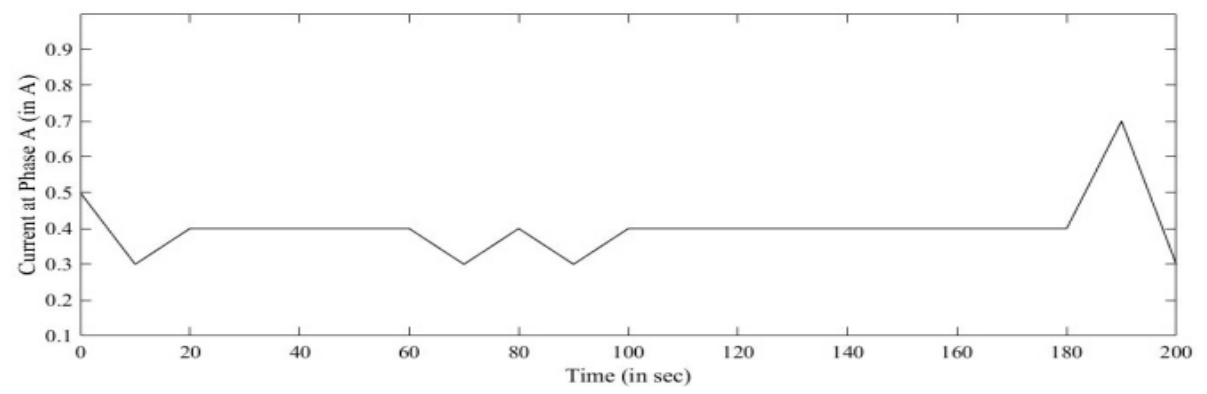

Figure 19. Cont. 

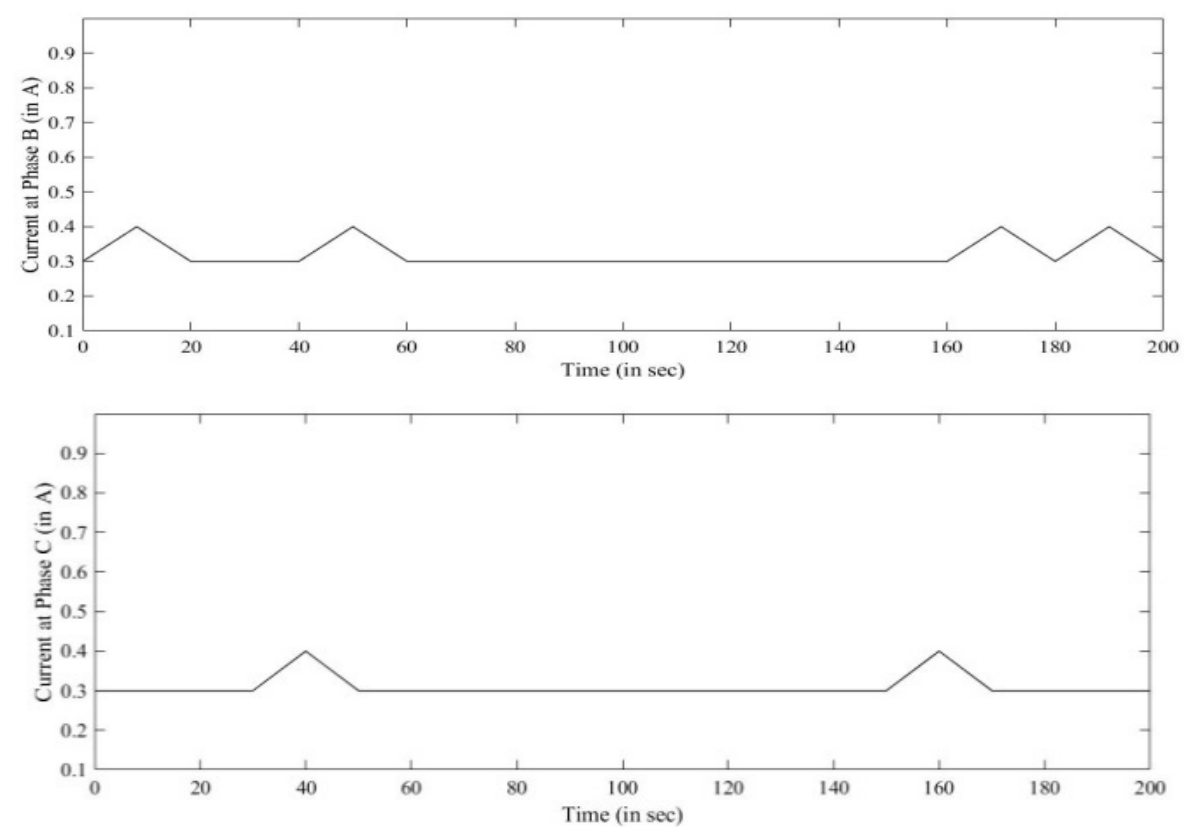

(b)

Figure 19. Current waveform of (a) output of inverter (b) at PCC.

It was observed from the Figure 18 that the average magnitude of the output voltage at each phase of the inverter $\left(\mathrm{V}_{\mathrm{i}_{\mathrm{a}} \mathrm{abc}}\right)$ with respect to time is near to the value $240 \mathrm{~V}$ or line voltage of $415 \mathrm{~V}$. Moreover the distortions at grid voltage $\left(\mathrm{V}_{\text {grid_abc }}\right)$ are more as compared to the inverter output voltage. To mitigate the difference in each phase voltage, an SRF-PLL based controller was used. Similarly, the response of rms phase current injected into the grid by voltage source converter and the grid current at each phase has was observed and is shown in Figure 19.

During the observations of the behavior of the current waveform, it is seen that small ripples were present in the grid current. However, at certain fractions of a second, the current from the inverter becomes constant with no ripples or distortions. The role of SRF-PLL based controller used is to regulate the injected current into the grid so as to maintain the constant level of the current waveform.

It is significant to measure and analyze the power wave of the grid before injecting the inverter current into the grid or before grid connection. The power wave at each phase is to be observed so as to reduce the error difference between the grid voltages and inverter output voltage and thus making the phase match with each other. The same conditions are for each phase current of the grid and inverter.

Figure 20 shows the power wave of the grid depicting the general trends of variations of the waveform.

The graphical result shows an assessment of frequency, which is nearly sinusoidal in nature with a measured value of nearly $50 \mathrm{~Hz}$. However, some difference was observed in the frequency of grid and inverter. The inverter frequency is nearly $50 \mathrm{~Hz}$ constant as presented in Figure 21 whereas the frequency varies for the grid but it was observed that the frequency variations of the grid were well within the limit as per the IEEE 519 [34]. Figure 22 shows the frequency spectrum at the point of common coupling (PCC) during the time span at a different number of events. Here, total 10 numbers of events were observed. It was observed that the frequency variation is from $50.03 \mathrm{~Hz}$ to $50.11 \mathrm{~Hz}$ out of which maximum times the value of frequency observed is $\mathrm{f}=50.09 \mathrm{~Hz}$, which compiles as per IEEE 519 standard. 


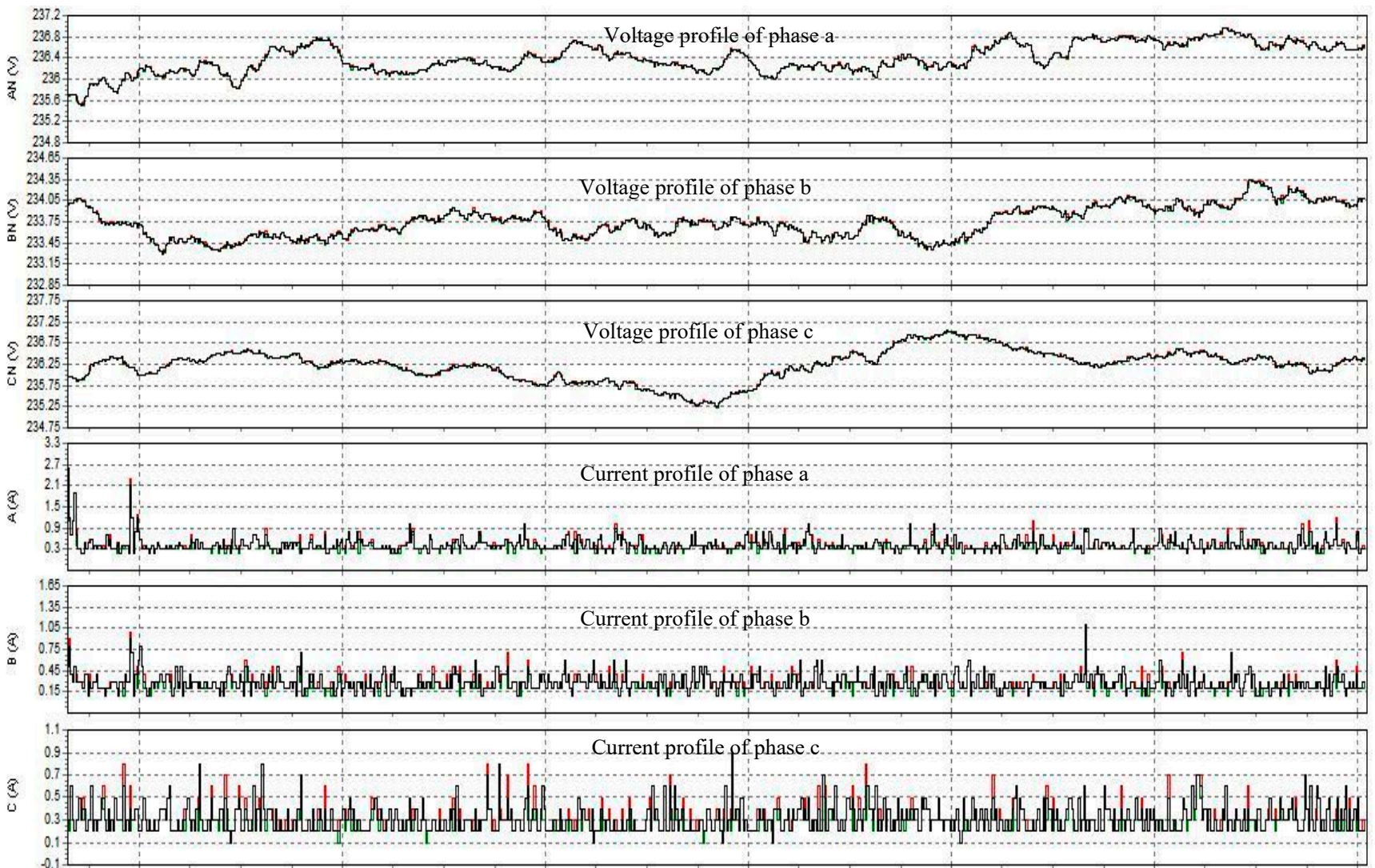

Figure 20. Power wave of the distribution grid.

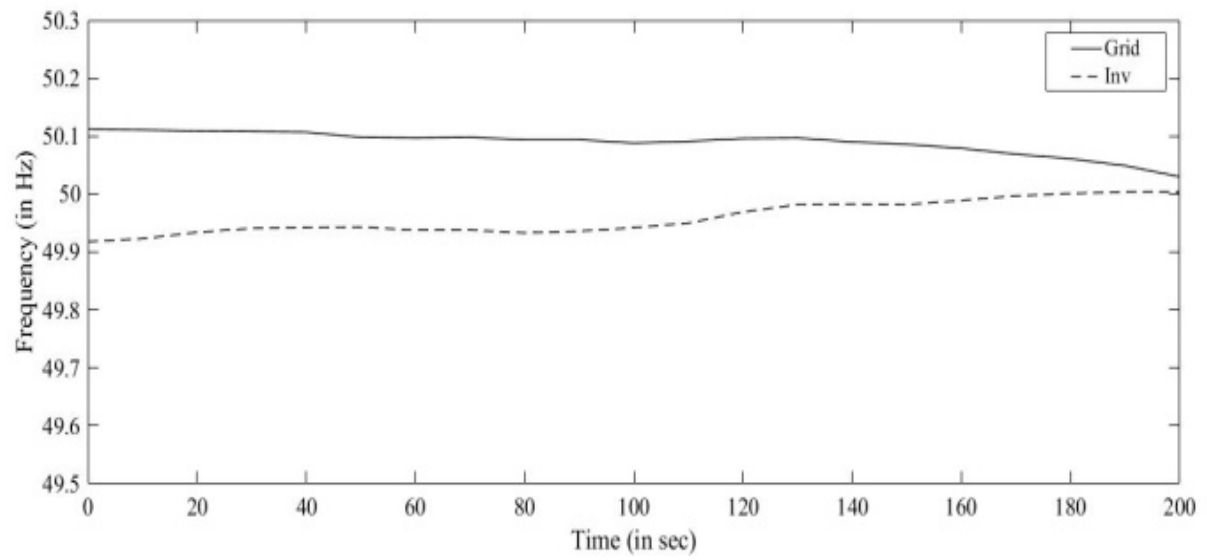

Figure 21. Frequency analysis of grid and inverter.

The graph in Figures 23 and 24 depicts the three-phase current and voltage analysis of the solar system and the grid side. It is seen from the figures that the waveform for solar system is pure sinusoidal whereas some notches has been observed at the tip point of the graphs as shown in Figure 24.

Due to load variation at the grid, the voltage profile of the grid side varies and some distortions and notches at the edge points were observed. To compensate for these variations, IGBTs of the inverter/VSC were fired so as to mitigate the distortions. However, the grid voltage and current are always the references while calculating the compensation or error signals. If the grid fails, the reference point value stands at zero and hence, the inverter shall not get the power and go in islanding mode of operation. 


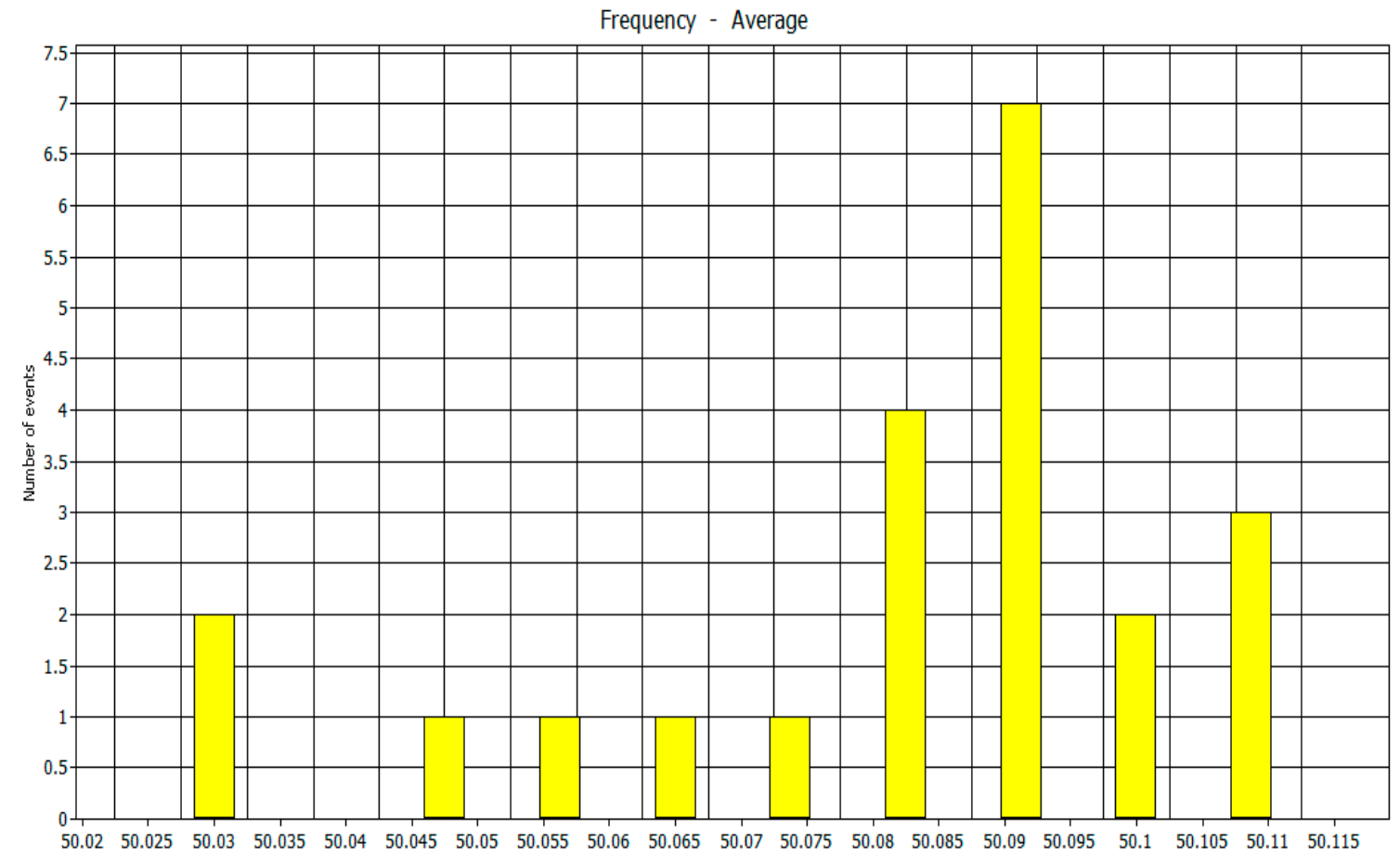

Figure 22. Frequency spectrum of grid.

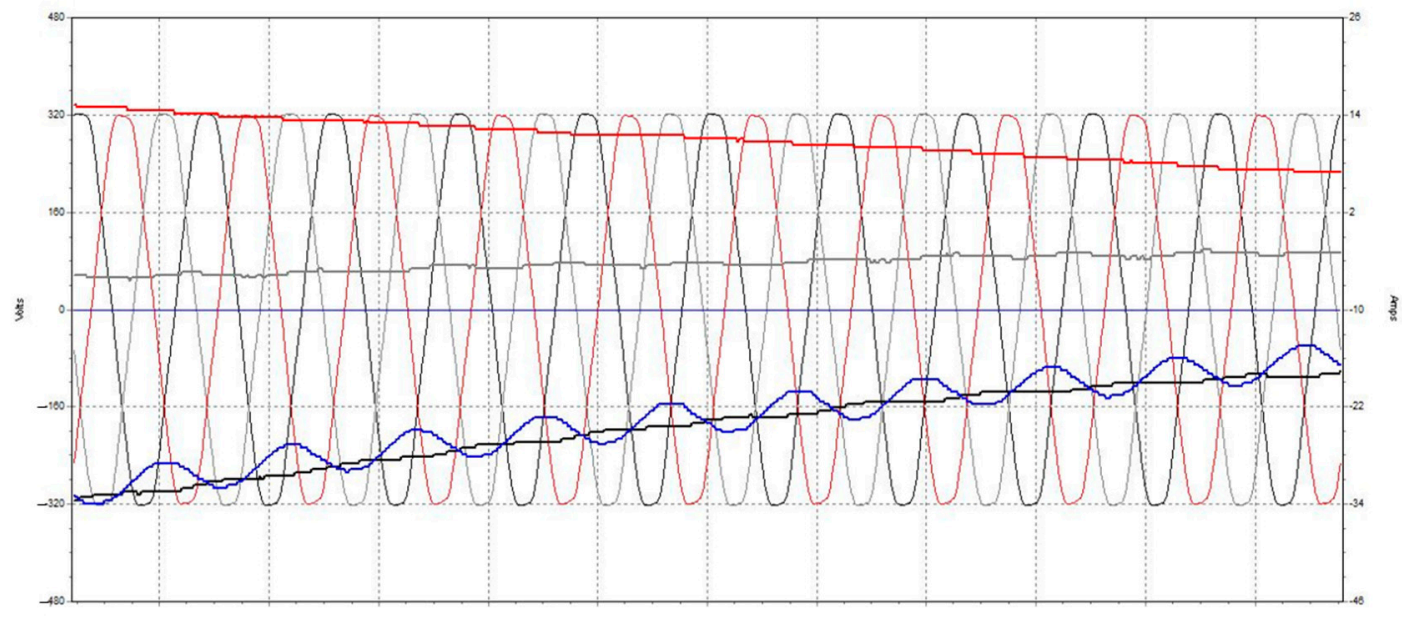

Figure 23. Current and voltage profile of solar PV system.

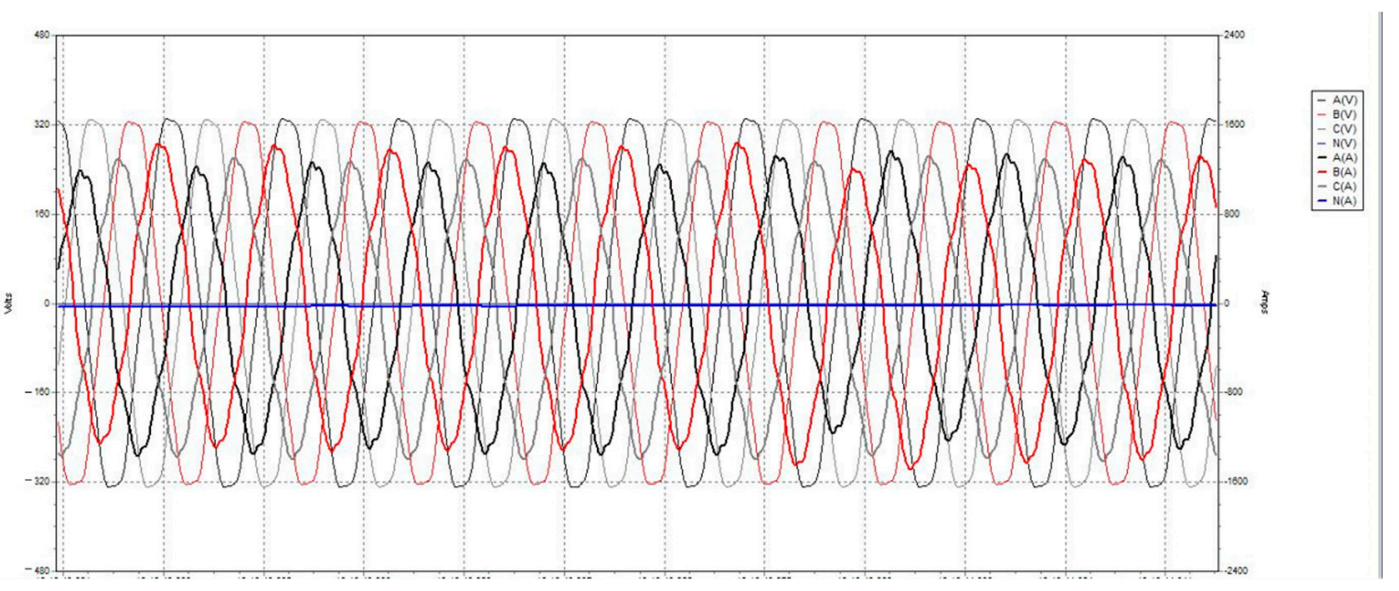

Figure 24. Current and voltage of profile of grid. 
The harmonic analysis of the grid side was also an important factor while the integration of the solar system takes place into the grid. For catering to the harmonics present in the grid, IEEE Std. 929-2000 [35] has to be followed. The analysis of the harmonics on the grid side was observed and is shown in Figure 25. It is seen that thethird, fifth, and seventh harmonics were present at each phase of the voltage. The $6 n \pm 1$ harmonic is always present in the grid system, which can be viewed in the harmonics analysis of the grid. It can be seen in Figure 25 that the harmonics present were approx. $3.4 \%$ which is less than the 5\% THD and hence complies with the IEEE 519 standard.

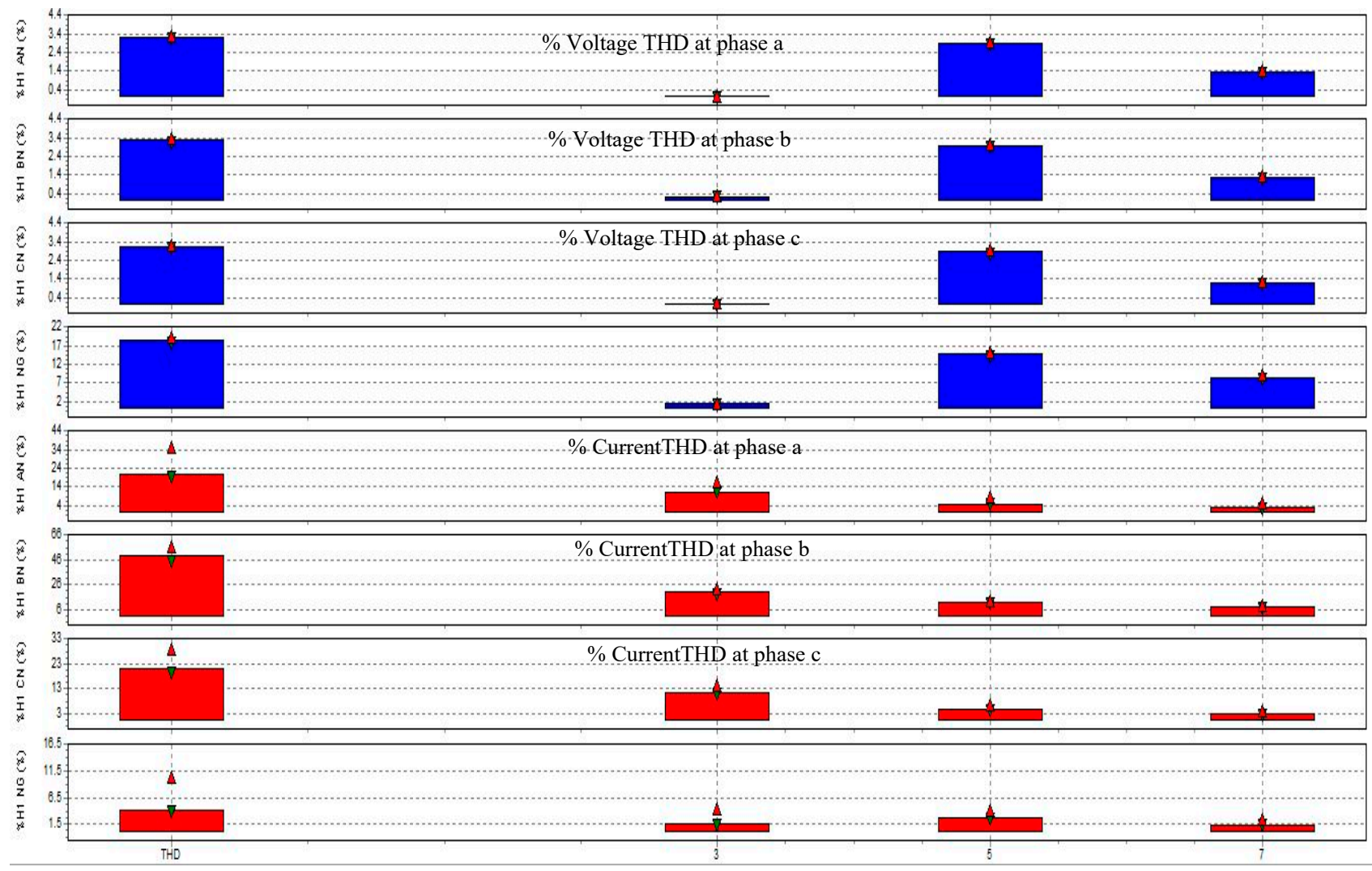

Figure 25. Harmonics analysis in grid.The system was tested with a nonlinear load of $1 \mathrm{HP}$ motor and resistive bulb load in the stand-alone as well as grid-connected mode, but no transients were observed during both modes of operations. However, some voltage drop was observed when load enhances.

The transients present in the network current travels in the distribution grid which is interconnected with the solar inverter. Hence, the current profile of the grid gets distorted, which is in general $120^{\circ}$ out of phase with each other. This happens due to variation in the load side power demand As a whole, it can be concluded that the grid current and voltage have sinusoidal behavior, and the same is required if grid integration is to take place with a stable frequency. It is further noticed that if there is any deviation from normal operating conditions, like failure of the reference grid, the inverter isolates from the grid and stops injecting voltages into the grid.

The active power feed from the grid tied inverter after receiving from the solar PV plant through the DC-DC converter is shown in Figure 26. It is observed that the power dipped at time $t=0.6 \mathrm{~s}$ and then resumed to the desired level at $t=1.6 \mathrm{~s}$. This is due to the variation of irradiance at the generation side of the system. Also, at $t=2 \mathrm{~s}$, a slight plunge was observed due to the variation in the temperature of the system at the input side. The results show that the power on the demand side varies as per the conditions on the generation side. The active power is directly proportional to the irradiance and hence a 
steep depletion was observed as recorded in Figure 26 whereas, it is inversely proportional to the temperature so trivial moderation was traced during such a time period.

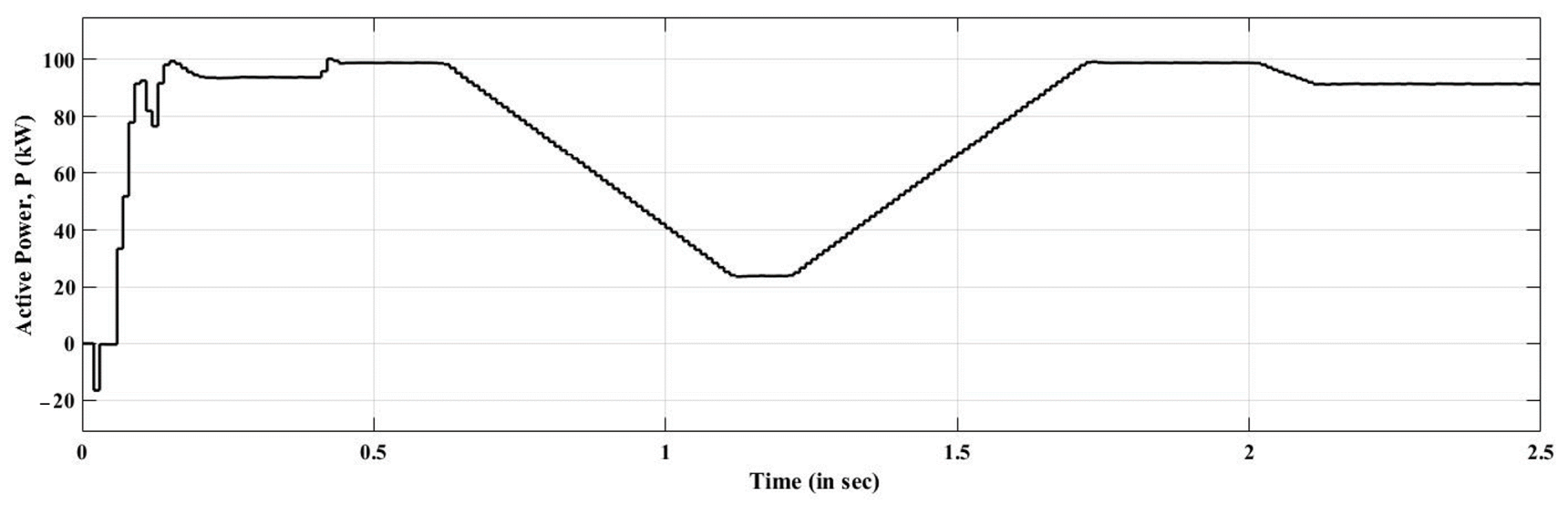

Figure 26. Active power received at the output of the grid tied inverter.

\section{Conclusions}

The proposed grid-connected model contains mainly a synchronous mode interleave boost converter, which has both advantages, that is, interleaved and synchronous operation due to which the more efficient system is obtained at the DC side. To cater to the irradiance variation on the DC side, the PSO based MPPT topology has been employed so as to track the maximum power point. The four-legged IGBT based VSC was used in the proposed model. For vetting the robustness of the proposed methodology and analysis of the solar PV system integrated into the distribution system, the system was designed and developed in Simulink environment. The system was simulated under distinct values of irradiance and temperature to examine the behavior of the proposed topology in the actual situation. A laboratory prototype of a $1.5 \mathrm{~kW}$ system was designed to analyze the system performance. The voltage, current and active power generated from the proposed scheme was observed under the variation of irradiance and temperature. The comparison of the synchronous mode and non-synchronous mode of the boost converter was recorded. It was seen that the proposed boost converter topology has fewer ripples and lesser stable time as compared to the conventional boost converters including interleaved facilities. The output voltage of the boost converter gets stabilized in a fraction of seconds. The conversion efficiency of the proposed converter topology was recorded to be more than $93 \%$ under different duty cycles. The frequency analysis of the grid was also remarked upon. The comparison of the frequency response of the grid tied inverter and utility grid was plotted and it was observed that the frequency response of the inverter is almost constant and disturbance-free with the local source being a little higher as compared to the grid frequency response. It is found that the variation of the frequency was from $50 \mathrm{~Hz}$ to $50.11 \mathrm{~Hz}$, which is not beyond the boundaries as per the IEEE 519 standard. The synchronous reference frame-based phase lock loop control strategy with PI controller was implemented to control and regulate the AC power and worked synchronously with the distribution grid. The analysis of the total harmonics distortion (THD) was carried out and recorded after the integration of the solar PV system with the distribution grid. It was observed that the third, fifth, and seventh harmonics were spotted but all were $<5 \%$, which is well within the range and complying with the IEEE standard 519.

Author Contributions: Conceptualization, A.D., M.R. and M.J.; Methodology, A.D., M.A. and M.R.; Validation, A.D. and M.J.; Formal Analysis, M.A., A.D., I.A. and M.R.; Resources, M.R. and M.A.; Writing-Original Draft, A.D. and M.R.; Writing-Review and Editing, A.D., I.A., M.R. and M.J.; Visualization, A.D.; Supervision, M.R. and M.J.; Funding Acquisition, M.A., I.A., and M.R. All authors have read and agreed to the published version of the manuscript. 
Funding: Researchers would like to thank the Deanship of Scientific Research, Qassim University for funding publication of this project.

Acknowledgments: Researchers would like to thank the Deanship of Scientific Research, Qassim University for funding the publication of this project.

Conflicts of Interest: The authors declare no conflict of interest.

\section{References}

1. Rashid, M.H. Power Electronics Circuits, Devices and Applications, 3rd ed.; Pearson: London, UK, 2006.

2. Subudhi, B.; Pradhan, R. A Comparative Study on Maximum Power Point Tracking Techniques for photovoltaic Power Systems; IEEE Transactions on Sustainable Energy: Piscataway Township, NJ, USA, 2013; Volume 4, pp. 89-98.

3. Nabil, K.; Nazih, M.; Rachid, O. General review and classification of different MPPT Techniques. Renew. Sustain. Energy Rev. 2017, 68, 1-18.

4. Alivarani, M.; Byamakesh, N.; Priti, D.; Kanungo, B.M. A review on MPPT techniques of PV system under partial shading condition. Renew. Sustain. Energy Rev. 2017, 80, 854-867.

5. Ahmed, J.; Salam, Z. An Enhanced Adaptive P\&O MPPT for Fast and Efficient Tracking under Varying Environmental Conditions. IEEE Trans. Sustain. Energy 2018, 9, 1487-1496.

6. Wang, Y.; Li, Y.; Ruan, X. High-Accuracy and Fast-Speed MPPT Methods for PV String Under Partially Shaded Conditions. IEEE Trans. Ind. Electron. 2016, 63, 235-245. [CrossRef]

7. Peng, B.; Ho, K.; Liu, Y. A Novel and Fast MPPT Method Suitable for Both Fast Changing and Partially Shaded Conditions. IEEE Trans. Ind. Electron. 2018, 65, 3240-3251. [CrossRef]

8. Li, X.; Wen, H.; Jiang, L.; Xiao, W.; Du, Y.; Zhao, C. An Improved MPPT Method for PV System with Fast-Converging Speed and Zero Oscillation. IEEE Trans. Ind. Appl. 2016, 52, 5051-5064. [CrossRef]

9. Sangwongwanich, A.; Blaabjerg, F. Mitigation of Interharmonics in PV Systems with Maximum Power Point Tracking Modification. IEEE Trans. Power Electron. 2019, 34, 8279-8282. [CrossRef]

10. Shaw, P. Modelling and analysis of an analogue MPPT-based PV battery charging system utilising dc-dc boost converter. IET Renew. Power Gener. 2019, 13, 1958-1967. [CrossRef]

11. Liu, H.; Hu, H.; Wu, H.; Xing, Y.; Batarseh, I. Overview of High-Step-Up Coupled-Inductor Boost Converters. IEEE J. Emerg. Sel. Top. Power Electron. 2016, 4, 689-704. [CrossRef]

12. Li, W.; He, X. Review of Nonisolated High-Step-Up DC/DC Converters in Photovoltaic Grid-Connected Applications. IEEE Trans. Ind. Electron. 2011, 58, 1239-1250. [CrossRef]

13. Forouzesh, M.; Siwakoti, Y.P.; Gorji, S.A.; Blaabjerg, F.; Lehman, B. Step-Up DC-DC Converters: A Comprehensive Review of Voltage-Boosting Techniques, Topologies, and Applications. IEEE Trans. Power Electron. 2017, 32, 9143-9178. [CrossRef]

14. Mousavi, A.; Das, P.; Moschopoulos, G. A Comparative Study of a New ZCS DC-DC Full-Bridge Boost Converter with a ZVS Active-Clamp Converter. IEEE Trans. Power Electron. 2012, 27, 1347-1358. [CrossRef]

15. Asim, A.; Aamir, A.; Hang, S.C.; Ahmad, E.; Nasrudin, A.R. Comparative analysis of high voltage gain DC-DC converter topologies for photovoltaic systems. Renew. Energy 2019, 136, 1147-1163.

16. Annop, N.; Sudarat, K. A Novel High Step-up DC-DC Converter for Photovoltaic Applications. Procedia Comput. Sci. 2016, 86, 409-412.

17. Dileep, G.; Singh, S.N. Selection of non-isolated DC-DC converters for solar photovoltaic system. Renew. Sustain. Energy Rev. 2017, 76, 1230-1247.

18. Joydip, J.; SahaHiranmay; Konika, D.B. A review of inverter topologies for single-phase grid-connected photovoltaic systems. Renew. Sustain. Energy Rev. 2017, 72, 1256-1270.

19. Amamra, S.; Meghriche, K.; Cherifi, A.; Francois, B. Multilevel Inverter Topology for Renewable Energy Grid Integra-tion. IEEE Trans. Ind. Electron. 2017, 64, 8855-8866. [CrossRef]

20. Li, W.; Gu, Y.; Luo, H.; Cui, W.; He, X.; Xia, C. Topology Review and Derivation Methodology of Single-Phase Transformerless Photovoltaic Inverters for Leakage Current Suppression. IEEE Trans. Ind. Electron. 2015, 62, 4537-4551. [CrossRef]

21. Li, T.; Cheng, Q. A comparative study of Z-source inverter and enhanced topologies. CES Trans. Electron. Mach. Syst. 2018, 2, 284-288. [CrossRef]

22. Wu, F.; Sun, B.; Duan, J.; Zhao, K. Online Variable Topology-Type Photovoltaic Grid-Connected Inverter. IEEE Trans. Ind. Electron. 2015, 62, 4814-4822. [CrossRef]

23. Raveendhra, D.; Pathak, M.K. Recent trends in solar PV inverter topologies. Solar Energy 2019, 183, 57-73.

24. Saleem, M.; Choi, K.-Y.; Kim, R.-Y. Resonance damping for an LCL filter type grid-connected inverter with active disturbance rejection control under grid impedance uncertainty. Int. J. Electron. Power Energy Syst. 2019, 109, 444-454. [CrossRef]

25. Shankar, V.A.; Umashankar, S.; Sanjeevikumar, P.; Mihet-Popa, L.; Fedák, V.; Ramachandaramurthy, V.K. Power Quality Performance Analysis of grid tied PV fed Parallel Pumping System under Normal and Vibrating Condition. Energy Procedia 2018, 145, 497-503. [CrossRef]

26. Kharrazi, A.; Sreeram, V.; Mishra, Y. Assessment techniques of the impact of grid-tied rooftop photovoltaic generation on the power quality of low voltage distribution network-A review. Renew. Sustain. Energy Rev. 2020, 120, 109643. [CrossRef] 
27. Hariri, M.H.M.; Desa, M.K.M.; Masri, S.; Zainuri, M.A.A.M. Grid-Connected PV Generation System-Components and Challenges: A Review. Energies 2020, 13, 4279. [CrossRef]

28. Naidu, R.P.K.; Meikandasivam, S. Power quality enhancement in a grid-connected hybrid system with coordinated PQ theory\& fractional order PID controller in DPFC. Sustain. Energy Grids Netw. 2020, 21. [CrossRef]

29. Al-Shetwi, A.Q.; Hannan, M.A.; Jern, K.P.; Alkahtani, A.A.; Abas, A.E.P. Power Quality Assessment of Grid-Connected PV System in Compliance with the Recent Integration Requirements. Electronics 2020, 9, 366. [CrossRef]

30. Teekaraman, Y.; Kuppusamy, R.; Baghaee, H.R.; Vukobratović, M.; Balkić, Z.; Nikolovski, S. Current Compensation in GridConnected VSCs using Advanced Fuzzy Logic-based Fluffy-Built SVPWM Switching. Energies 2020, 13, 1259. [CrossRef]

31. Revathi, B.S.; Prabhakar, M. Non isolated high gain DC-DC converter topologies for PV applications-A comprehensive review. Renew. Sustain. Energy Rev. 2016, 66, 920-933. [CrossRef]

32. Hinov, N.; Arnaudov, D.; Valchev, V.; Vuchev, S. Comparative Loss Analysis of Boost and Synchronous Boost DC-DC Con-Verters; XXVI International Scientific Conference Electronics (ET): Sozopol, Bulgaria, 2017; pp. 1-4.

33. dSPACE DS-1104. Hardware Installation and Configuration and Control Desk Experiment Guide; dSPACE: Paderborn, Germany, 2004.

34. IEEE Guide for Harmonic Control and Reactive Compensation of Static Power Convertors, IEEE 519-1981. April 1981. Available online: https: / / ieeexplore.ieee.org/abstract/document/27808 (accessed on 13 February 2021).

35. Recommended Practice for Utility Interface of Photovoltaic Systems, IEEE Std 929-2000. 2000. Available online: https://standards. ieee.org/standard/929-2000.html (accessed on 13 February 2021). 